Revista de Estudios Histórico-Jurídicos

[Sección Derecho Romano]

XXXIV (Valparaíso, Chile, 2012)

[pp. 127 - 163]

\title{
El CONCEPTO DE “RES” EN LOS JURISTAS ROMANOS, II: LAS "RES COMMUNES OMNIUM"
}

[The concept of "res" in the Roman jurists, II: The "res communes omnium”]

\author{
Juan David Terrazas Ponce*
}

Universidad Andrés Bello, Santiago de Chile

\begin{abstract}
RESUMEN
El artículo tiene como propósito discutir el concepto de res communes omnium, su origen, significado y sistemática. Después de examinar las opiniones de los más importantes romanistas que han tratado el tema, se concluye que ya en el periodo clásico hay pleno reconocimiento a la categoría, aunque bajo una diversa nomenclatura, la que pasa al Corpus Iuris, y que fue el jurista Marciano quien habría incluido el aqua profluens en esta clase de cosas.
\end{abstract}

Palabras Clave

Res - Res communes omnium.
Abstract

The article aims at discussing the concept of res communes omnium, its origin, meaning and the way it is organized. After examining the opinions of the most important Romanists that have dealt with the matter, it can be inferred that even in the Classical Period there was full recognition of the category, but with a different nomenclature, which was included in the Cospus Iuris, and that it was the jurist Marcianus who would have included aqua profluens in this kind of things.

KEYWORDS

Res - Res communes omnium.

ReCiBIDO el 1 de octubre de 2011 y ACEPTADO el 2 de mayo de 2012

* Profesor de Derecho romano de la Facultad de Derecho de la Universidad Nacional Andrés Bello. Dirección postal: Bellavista 0121, Santiago, Chile. Dirección electrónica: jterrazas@unab.cl 


\section{INTRODUCCIÓN}

En el número correspondiente al año 2010 de esta revista ${ }^{1}$, publicamos un artículo que hacía referencia al concepto de "res" en los juristas clásicos, todo ello en orden a dar un primer paso, para desentrañar adecuadamente las clasificaciones de las cosas que aparecen en las fuentes y, particularmente aquella, supuestamente debida a Marciano y que consagra la categoría de "res communes omnium".

Con este objetivo, parece del todo conveniente, antes de adentrarnos en la sistemática de Marciano detenernos, aun cuando sea someramente, en el contexto histórico en el que este maestro tardo-clásico desarrolla su actividad, pues como fácilmente se puede entender, este factor determinará en gran medida las orientaciones de su obra. Sobre el particular, los datos biográficos son oscuros y escasos ${ }^{2}$ : lo más probable es que haya vivido entre fines del siglo II y la primera mitad del siglo III de nuestra era ${ }^{3}$, desarrollando su actividad fundamentalmente en la época de los Severo ${ }^{4}$, al punto de que Ferrini teoriza en torno a que sus obras (De appellationibus libri II; De delatoribus liber singularis; Ad formulam hypotecariam liber singularis; Institutionum libri XVI; De iudiciis publicis liber II; Regularum libri V; Ad senatusconsultum Turpillianum liber singularis) se habrían escrito después de la muerte de Caracalla ${ }^{5}$, opinión que hoy se asume sin dificultades.

Sus Institutiones son las que han suscitado mayor atención e interés por parte de la romanística ${ }^{6}$, aunque la valoración de la misma es uno de los puntos más controvertidos, lo que podría resumirse en el parecer de Schulz ${ }^{7}$, quien no duda en tildarlo de "un extraño trabajo" y termina por concebir la idea de que en realidad se trata de un libro póstumo, resultado de la fusión de dos obras: un estudio incompleto para unas Institutiones y un estudio preparatorio para unos Digesta sistemáticos.

Por lo tanto, pareciera ser bastante razonable tener como cierta la época en

\footnotetext{
${ }^{1}$ Terrazas Ponce, Juan David, El concepto de “res publicae”, I: La noción de “res” en el lenguaje de los juristas romanos, en Revista de Estudios Histórico-Jurídicos, 32 (2010), pp. 127 ss.

${ }^{2}$ De Giovanni, Lucio, Giuristi Severiani. Elio Marciano (Napoli, M. D’Auria Editore, 1989). Basamos nuestras apreciaciones en este trabajo, pues en él no sólo se ordenan los escasos antecedentes biográficos de Marciano, sino también el contenido de sus obras.

${ }^{3}$ Honoré, A.M., The Severan Lawyers: a Preliminary Survey, en SDHI., 28 (1962), pp. 162 ss., entrega algunos datos más, que coinciden con lo ya expresado: habría nacido en torno al año 180 d.C., desempeñándose como asistente de Ulpiano entre los años 205 y 212, magister libellorum entre el 229 y el 235 y, de acuerdo a las conclusiones de este mismo autor, su obra habría sido compuesta entre los años 217 y 222.

${ }^{4}$ Orestano, Riccardo, s.v. "Marciano Elio", en NNDI., X, pp. 254 ss.

${ }^{5}$ Ferrini, Contardo, Intorno alle Istituzioni di Marciano, en Opere di Contardo Ferrini, II, pp. 285 ss. De hecho en varios pasajes de las Institutas se hace referencia a Septimio Severo y Caracalla, utilizando la expresión "divi Severus et Antoninus", con la que se suele indicar la persona de un emperador ya muerto. En el mismo sentido, véase DE Giovanni, Lucio, Per un studio delle "Institutiones" di Marciano, en SDHI., 49 (1983), pp. 94 ss.

${ }^{6}$ Como muestra de aquello podemos, además del artículo recién referido de FERRINI, citar este otro del mismo: Sulla palingensi delle Istituzioni di Marciano, en Opere di Contardo Ferrini, II, pp. 277 ss.

${ }^{7}$ Schulz, Fritz, History of Roman Legal Science (Oxford, 1935), p. 173.
} 
que MARCiano desarrolló su actividad y esto no es menor, pues como es sabido, se trata de un periodo de profundos cambios que incluyen, entre otros, aspectos tan relevantes como el de la ciudadanía, la que es extendida a todos los habitantes libres del Imperio con la constitutio Antoniniana ${ }^{8}$.

Así las cosas, hay que conceder que las Institutiones de Marciano se encuentran contextualizadas en un ambiente lleno de convulsiones y podrían ser el resultado de la preocupación principal para aquella época: adecuar el derecho a una nueva realidad política y social ${ }^{9}$. También se debe admitir que Marciano escribe en una época en que la jurisprudencia, en las obras de carácter didáctico, presta especial atención en definir y clasificar de un modo más detenido los conceptos jurídicos ${ }^{10}$. En este sentido, Buckland ${ }^{11}$ ha podido marcar la presencia de esta tendencia en la obra de Marciano, en casos como el de la concepción del usufructo y la servidumbre, la sistemática exposición sobre la mora ex persona o ex re $e^{12}$ y en algunas otras materias donde se muestra, aparentemente, como un innovador: las causas de la esclavitud, de los ingenui y de las res communes omnium ${ }^{13}$.

Precisamente, este último tema este último, el de las res communes ómnium, es el que monopolizará nuestra atención y en torno al cual se han suscitado fuertes controversias entre los romanistas ${ }^{14}$, particularmente porque su inclusión en el Corpus Iuris, plantea dudas, toda vez que esta categoría es totalmente ignorada por Gayo, cuyas Institutiones son el modelo fundamental de las propias de Justiniano. Por ello, no debe extrañar que las raices de las res communes omnium no sean posible de pesquisar más que en Marciano, aun cuando, como veremos más adelante, incluso sea discutible si se trató de una creación de él, o sólo de una nomenclatura distinta para una clasificación ya conocida.

Para un mejor estudio, nos detendremos en los apartados siguientes en las tesis de los principales autores que han tratado el tema de las res communes omnium

${ }^{8}$ De Martino, Francesco, Storia della costituzione romana (Napoli, Jovene, 1972-1990), pp. 777 ss.; De Giovanni, Lucio, Per un studio delle 'Institutiones' di Marciano, en SDHI., 49 (1983), pp. 102 ss. Pese a la importancia de la constitutio Antoniniana, no debemos pasar por alto la apreciación de Talamanca, en orden a que esta constitución no tuvo iguales repercusiones entre los juristas, pues se nota mucho más su influencia en Marciano y Modestino, que en Paulo y Ulpiano. Véase TALAMANCA, Mario, Gli ordinamenti provinciali nella prospectiva dei giurisiti tardoclassici, en Atti di un incontro tra storici e giuristi sull tema: istituzioni giuridiche e realità politiche nel tardo impero (III-V sec. d.C.) (Milano, 1976), pp. $102 \mathrm{ss.}$

${ }^{9}$ De Giovanni, Lucio, Giuristi Severiani. Elio Marciano, cit. (n. 8), p. 21.

${ }^{10}$ VILLEY, Michel, Recherches sur la littérature didactique du droit Romain (Paris, 1945), pp. 70 ss. Prueba de ello son las Regulae de Modestino y las Definitiones de Papiniano, contemporáneas a la obra de Marciano.

${ }^{11}$ BucKland, W. W., "Marcian”, en Studi Riccobono, I, pp. 277 ss.

${ }^{12}$ D. $8,1,1$; D. 22,1,32; D. 48,22,5.

${ }^{13}$ Sin perjuicio de haberse destacado en varias oportunidades, la categoría de res communis omnium, es particularmente sensible para el estudio de la clasificación de las cosas a lo largo de la historia del Derecho. Sobre este particular, Véase Miele, Alberto, "Res publica", "res communis omnium", "res nullius": Grozio e le fonti romane sul diritto del mare, en Index, 26 (1988), pp. 383 ss.

${ }^{14}$ RobBe, Ubaldo, La non classcitá delle "res comunes omnium", en Studi in onore di Andrea Arena, IV, pp. 2157 ss., pp. 112 ss. 
y su relación con Marciano. Con posterioridad delinearemos nuestra posición sobre el tema.

\section{El RECHAZO DE BONFANTE}

El ataque más frontal en contra de la categoría de res communes omnium proviene de Bonfante ${ }^{15}$, quien sostiene que el hecho de que sean referidas sólo por Marciano demuestra que son una creación de este maestro, el que la habría rescatado de la tradición literaria. Por lo mismo, añade, resulta totalmente inexistente en el derecho clásico y ciertamente no tiene ningún valor práctico en el derecho justinianeo ${ }^{16}$.

En efecto, prosigue nuestro autor, esta categoría no sólo es ignorada por Gayo, sino por todos los juristas clásicos, lo que resulta evidente al analizar el elenco de las cosas que Marciano incluye como tales: el aire, salvo dos textos ${ }^{17}$, no es referido por las fuentes; el aqua profluens también aparece en dos fragmentos ${ }^{18}$, pero absolutamente descontextualizada del asunto de las res communes omnium. Sólo en el caso del mar y sus costas, tenemos alusiones profusas en las fuentes, pero en las que se les califica como res publicae o publicae iuris gentium y nunca como res communes omnium ${ }^{19}$. A partir de este mismo análisis, agrega, es posible teorizar en torno a que Marciano no haya creado esta categoría como distinta de las res publicae, ya que podría tratarse sólo de una diversa terminología para estas mismas cosas, especialmente si se trae a colación el argumento de que el texto de aquel jurista, incluido en el Digesto, no menciona las res publicae. Para Bonfante, el asunto es bastante claro: de la evidencia textual, particularmente del hecho de que Marciano incluyese entre las res communes omnium todas las cosas que otros juristas llaman publicae iuris gentium o iure gentium y que él mismo utilizara la expresión "iuris gentium" ${ }^{20}$, da cuenta que sólo se trata de una nueva terminología para referirse a un grupo de cosas perfectamente individualizado: las res publicae.

Incluso hay argumentos, dice Bonfante, en virtud de los cuales se podría dudar de la clasicidad de esta categoría, pues ella se presenta como una aplicación del ius naturale ("naturali iure comuna sunt omnium haec") y de acuerdo con Perozzi ${ }^{21}$, la diferenciación entre éste, el ius civile y el ius gentium es de Justiniano.

Sin perjuicio de lo anterior, existe un antecedente que sirve tanto para afirmar la paternidad marcianea de esta categoría, como también para cimentar dudas

${ }^{15}$ Bonfante, Pietro, Corso di Diritto Romano. La proprietà (Milano, Giuffre, 1966), pp. 42 ss.

${ }^{16} \mathrm{El}$ mismo camino, con abundante bibliografía y recopilación de opiniones de diversos autores, sigue RobBE, cit. (n. 14), pp. 212 ss.

${ }^{17}$ D. $43,8,3,1$ y D. $47,10,13,7$.

${ }^{18}$ D. $39,3,1,22$ y CI. $3,34,7$.

${ }^{19}$ Cic., Top. 7,32; D. 50,16,112 (Iav., 11 ex Cass.); D. 1,8,10 (Pomp., 6 ex Plaut.); D. 41,1,14,1 (Nerat., 5 membr.); D. 43,8,3 pr. (Ulp., 66 ed.); D. 41,1,50 (Pomp., 6 ex Plaut.); D. 43,8,4 (Scaev., 5 resp.); D. 41,3,45 pr. (Pap., 10 resp.); D. 41,1,65,1 (Lab. 6 pith. Paul. ep.).

${ }^{20}$ D. $1,8,4$ pr. (Marcian., 3 inst.).

${ }^{21}$ Perozzi, Silvio, Istituzioni di diritto romano (Firenze, Barbera, 1906-1908), pp. 66-67. 
respecto de su origen: si bien las res communes omnium no son familiares para el mundo jurídico, sí lo son para el filosófico ${ }^{22}$ y de todos los juristas y maestros de derecho, Marciano es el más conocedor de este tipo de literatura, tal como evidencia sus alusiones a Homero, Cicerón, Demóstenes, Virgilio y Crisipo ${ }^{23}$.

En orden a reforzar su explicación, Bonfante se retrotrae al Brachylogus, manual del alto medioveo, fiel reflejo de la doctrina justinianea: en él se suprimen las res communes, que pasan a formar parte de las res publicae ${ }^{24}$. Irnerio aplica el concepto a propósito del ius naturale: "res communes communia omnium animalium dicuntur: publica hominum tantum” y, entre estas cosas comunes a los hombres y a los animales, incorpora los ríos ${ }^{25}$, tesis que luego persistirá en otros, como ocurre con $\mathrm{Azo}^{26}$.

Respecto de la autonomía y significado jurídico de la categoría en el Derecho Romano, Bonfante señala que, en lo que se refiere al derecho clásico, la nomenclatura sólo aparece en Marciano. De hecho, es posible que este maestro haya incluido dentro de la categoría también los ríos: tal vez él no pone la categoría de res publicae, sino que incluía en las res communes aquellas que los juristas llaman res publicae iuris gentium (sustancialmente el agua) y crea la categoría autónoma de res universitatis para los edificios y las obras públicas no sólo de la ciudad, sino también del Estado.

En el derecho justinianeo el concepto de res communes es asumido como fundamental tanto en el Digesto como en las Institutiones, distinto de las res publicae populi romani y de las res universitatis. Pero su valor es meramente teórico, a lo menos si consideramos la generalidad de la categoría, especialmente por el hecho de que está integrada por cosas de diversa naturaleza.

Siguiendo esta misma línea, Mommsen ${ }^{27}$ se pronuncia en contra de la existencia de las res communes, en la época clásica, como también lo hace $\operatorname{Costa}^{28}$, el que motivado principalmente por la opinión de Celso respecto de las $\operatorname{costas}^{29}$, cree superar la dificultad, entendiendo que en el elenco respectivo sólo se incluyó el borde costero con Justiniano, lo que importa dar por interpolada la frase "et per hoc litora maris" en D. 1,8,2,1 (Marcian., 3 inst.) y "et litora " en D. 47,10,13,7 (Ulp., 57 ed.). Además, en lo que dice relación con el mar, éste debe considerarse como res communes omnium, sólo en la medida que se refiera al altamar, ya que el mar territorial sería una cosa pública. Arangio-Ruiz acepta sin trabas la tesis

${ }^{22}$ Cic., Pro Roscio 26,72; Cic., De off., 3,16,52; Virg., Aen. 7,229; Ovid., Metam., 3,136.136; 6,349.351.

${ }^{23}$ Bonfante, Pietro, Corso di Diritto Romano, La proprietà, cit. (n. 15), p. 55-6.

${ }^{24}$ Brach. Iur. Civ., II, 10,1,1.

${ }^{25}$ Summa Inst., 2,1.

${ }^{26}$ Bonfante, Pietro, Corso di Diritto Romano, La proprietà, cit. (n. 15), p. 58.

${ }^{27}$ Mommsen, Thedoro, Sopra una iscrizione scoperta in Frisia, en BIDR., 2 (1889), pp. 131 ss.

${ }^{28}$ Costa, Emilio, Le acque nell diritt romano (Bologna, Nicola Zanichelli, 1918) pp. 21 ss.

${ }^{29}$ D. 43,8,3 (Cel., 39 dig.). 
antes expuesta, asegurando que la categoría de las res communes es absolutamente justinianea ${ }^{30}$.

Por último, y en una posición todavía más extrema, Biondi ${ }^{31}$, rechaza totalmente la autonomía de las res communes omnium, pues para él los términos "público" y "común” no son contradictorios.

\section{La ACEPTACiÓN DE SCIALOIA}

De acuerdo a este gran romanista ${ }^{32}$, la diferenciación entre las res communes omnium y res publicae es exacta y refleja una distinción real, pues si bien en ambas categorías se incluyen cosas que pueden ser usadas por todos, en el caso de las primeras este uso no puede ser prohibido o limitado, situación que si puede dar respecto de las segundas, las que además pertenecen al Estado o a otro ente público.

Para tener una mayor claridad al respecto, condiciona nuestro autor, se debe establecer el significado de los términos "publicus" y “communis”. En latín el sentido técnico-jurídico de ambas palabras no es siempre el mismo y, por ello, hacer la diferenciación es necesario para enfrentar adecuadamente los textos: "publicus" significa perteneciente al pueblo o al Estado (populus Romanus) y también aquello que es de privados, pero es sujeto de uso público. En algunos casos "publicus" se usa como sinónimo de "communis". Sin embargo, esta última palabra es más bien utilizada en un sentido diverso: para referirse a la coparticipación de más personas en una cosa (condominio); o para indicar la sujeción de una cosa al uso popular, caso en el cual se confunde con "publicus". En las fuentes se dicen cosas públicas aquellas que pertenecen al Estado (que son las res publicae en sentido técnico), las cosas communes omnium (mar y sus costas) y las cosas privadas sujetas a uso público (orillas de los ríos). Los textos llaman res communes además de aquellas que propiamente reciben esa denominación, las que pertenecen a los municipios y otras entidades diversas del Estado, las cosas públicas y aquellas tenidas en condominio. Entonces "publicus" y "communis", pueden usarse indistintamente.

Este fenómeno que se puede tildar de lingüístico, debe ser considerado en la interpretación de los textos, pero en lo que interesa a nosotros Marciano ha seguido una tradición largamente difundida en ámbitos no jurídicos. Es verdad que en muchos textos estas cosas son calificadas de res publicae, pero dada la incerteza y la variabilidad del significado de "publicus", ello permite discutir la tesis de Bonfante, quien a partir del texto contenido en D. 43,8,3 pr. (Cel., 39 dig.); en el que Celso dice que, a su modo de ver, las costas del mar son res populi romani ("populi romani esse arbitror"), concluye que en el derecho clásico las costas del mar son una res publica.

\footnotetext{
${ }^{30}$ Arangio-Ruiz, Vincenzo, Istituzioni di Diritto Romano (Napoli, Jovene, 1994), p. 31

${ }^{31}$ Biondi, Biondo, La condizione giuridica del mare e del "litus maris", en Studi in onore di Silvio Perozzi, pp. 259 ss.

${ }^{32}$ SCIALOJA, Vittorio, Teoria della proprietà nel diritto romano (Roma, Edita Pietro Bonfante, 1928), pp. 125 ss.
} n. 1. 
Pero la verdad, es que el texto claramente refiere la opinión personal de Celso, lo que da a entender que esa no es la común en los demás juristas.

\section{El apoyo de Grosso a la ClASicidad dE LA CATEGoría}

Este autor defiende la clasicidad de la categoría de las res communes omnium, al menos en el sentido de que la paternidad de Marciano no puede ser puesta en $\mathrm{duda}^{33}$, pero no cree que se trate de una opinión aislada de dicho maestro, sino que por el contrario, ella ya se encontraba en Celso y también en Ulpiano.

Prosigue Grosso razonando en torno al hecho de que si la categoría de las res communis omnium no es considerada por otros juristas romanos, ello no significa necesariamente que la distinción responde a una visión aislada de Marciano, pues si está presente tanto en Celso como en Ulpiano, al punto que se puede decir que la formación y desarrollo de este especie de cosa es el resultado de la obra de la jurisprudencia en su conjunto ${ }^{34}$.

El fundamento de la categoría se refiere al hecho de que la cosa, dada su naturaleza no pertenece a nadie y son destinadas al uso de todos, esto es ciudadanos y aquellos que no lo son: ello es propio del aire y por analogía, se aplica también al aqua profluens, al mar y, en opinión de Marciano, a sus costas.

Por lo demás, existe todo un régimen de estas res communes omnium, que se refleja en consecuencias jurídicas, sea en lo que dice relación con la exclusión de relaciones patrimoniales privadas, sea por el uso común al que están destinadas. Resulta claro, concluye Grosso, que el carácter de las res communes omnium, encuentra su origen en la particular configuración del mar y sus costas, así como las asimilación del primero al aire. Ahora bien, al incluir el pasaje de Marciano en el Digesto, se genera el problema de que en él no se incluyen las res publicae, lo que ha llevado a explicar esta situación por dos vías: la primera supone que Marciano no las mencionaba, pues las dividió en res communes omnium y res universitatis, y la segunda, que fue borrada accidentalmente por los compiladores ${ }^{35}$.

Está probado que Marciano es bastante instruido tanto en literatura como filosofía y que la categoría de las res communes más que jurídica es producto de la especulación filosófica, pero ella está aceptada en los juristas más antiguos como Neracio $^{36}$ y Celso ${ }^{37}$, teniendo eco en Paulo ${ }^{38}$ y Ulpiano ${ }^{39}$. Sin embargo, es Marciano quien la presenta como una clasificación sistemática y la trasnforma en una verdadera categoría de cosa, distinta de las públicas. Nuestro maestro tardo-clásico traduce una perspectiva prejurídica, esto es, la posibilidad de que

${ }^{33}$ Grosso, Giuseppe, Corso di diritto romano. Le cose (Torino, Giappichelli, 1941) pp. 89 ss.; El mismo, Problemi sistematici nel diritto romano. Cose, contratti (Torino, Giappichelli, 1974), pp. 24 ss.

${ }^{34}$ Ibíd., p. 97.

${ }^{35}$ Ibíd., pp. 91 ss.

${ }^{36}$ D. 41,1,14 (Nerat., 5 membr.).

${ }^{37}$ D. 43,8,3,1 (Cel., 39 dig.).

${ }^{38}$ D. 18,1,51 (Paul., 21 ed.).

${ }^{39}$ D. 47,10,13,7 (Ulp., 57 ed.). 
cualquiera pueda utilizar una cosa, en una verdadera y propia categoría jurídica a la que dio el nombre de res communes omnium, totalmente atingente a su formación literaria y filosófica, lo que finalmente lo lleva generar el elenco ya conocido de cosas incluidas en ella: aire, agua corriente, mar y sus costas.

Gayo, por el contrario, en la res humani iuris, contrapone cosa pública a cosa privada; y esto significa que para él las costas y el mar deben ser consideradas como públicas, mientras el aire y el agua corriente no podían ser considerados realmente como res $^{40}$.

\section{La DEFENSA ABSOluta de Branca}

La más fuerte y fundada defensa de las res communes omnium es la realizada por Branca ${ }^{41}$, quien trata de demostrar no sólo la autenticidad, sino también la calidad de la clasificación marcianea y, después de haber reconstruido el régimen diferencial, llega a determinar el fundamento y la importancia de las tres distintas categorías cosas (res communes omnium, res publicae, res universitatis) en el sistema clásico y en el bizantino.

1. Para demostrar su teoría ${ }^{42}$, inicia el discurso señalando que resulta notorio que en las Institutiones de Justiniano se dividen las cosas, que no son de privados o nullius, en communes (aire, aqua profluens, mar y sus costas), publicae (puertos, ríos, plazas) y universitatis (teatros, estadios y similares cosas de la civitas).

Ahora, si se pretende sostener, a lo menos en el derecho justinianeo la existencia de estas tres categorías de cosas, la lógica indica que deberían existir tres regímenes jurídicos para regular cada categoría de ellas, al punto de que si se logra identificar esta tripartición en lo que dice relación con la regulación jurídica, entonces la clasificación cobra sentido; si por el contrario aquello no es posible, se restará valor a esta diferenciación. Para estos efectos Branca recorre un camino en el que hace una serie de apreciaciones, todas ellas que permiten hacer las siguientes precisiones, respecto del esquema presentado en el Corpus Iuris:

a) La distinción entre res publicae y res universitatis no se funda, en la peculariedad del régimen de alguna de estas categorías respecto de la otra. El uso de ellas es libre a todos los ciudadanos; la necesidad de un permiso preventivo en orden a los actos que excedan el uso ordinario también es común, siendo la legitimidad y frecuencia de concesiones de goce exclusivo a los privados reconocida de la misma manera. Si todo esto no resulta en modo explícito de las fuentes, que se limitan a tratar, en especial en el libro 43 del Digesto, de las res publicae en general, dicho silencio es precisamente a favor de la analogía de régimen: el interdicto fundamental "ne quid in loco publico fiat" (D. 43,8) y "de loco publico fruendo" (D. 43,9) tutelan a posteriori el uso y la concesión de lugar del Estado como de aquellos de

\footnotetext{
${ }^{40}$ De esta forma Grosso, participa de nuestra idea de que existen cosas que no pueden ser calificadas de "res".

${ }^{41}$ Branca, Giuseppe, Le cose "extra patrimonium humani iuris" (Torino, Giappichelli, 1941), pp. 4 ss.

${ }^{42}$ Ibíd., pp. 64 ss.
} 
toda la civitas. Que el órgano administrativo del Estado fuera distinto de aquellos de las varias civitates, poco importa, pues esto no implica una verdadera y sustancial diferencia entre las dos categorías (res publicae y res universitatis).

b) Pero si analizamos el caso de los ríos y sus orillas, confrontándolos con las otras res publicae, pese a no existir diversidad en cuanto al uso libre y común, sí se notan tres diferencias notables: en primer lugar, la singularidad consistente en el hecho de que el álveo es de dominio privado; luego el hecho de que el régimen de la derivación, que es libre para el agua de los ríos, no lo es en el caso de aguas conducidas a través de canales o en otros lugares públicos, lo que demuestra un criterio distinto en la valoración del concepto de usus; y por último, desde un punto de vista formal, la presencia de la actio iniuriarum, que sólo es posible respecto del suelo público para tutela del uso de parte de todos.

Pese a esto, es mucho más factible una solución de continuidad entre los ríos y las demás cosas públicas, que entre estas últimas y las res universitatis, lo que de una mirada atenta a las fuentes, tampoco puede sorprender, toda vez que los ríos pertenecen a una clase de cosa distinta de aquellas otras de uso común y de hecho en las principales sedes materiae ${ }^{43}$, sólo estos figuran como res publica, junto con los puertos.

c) Comparando ahora el régimen del mar con el de los ríos, se puede decir que no hay grandes diferencias: uso libre y necesidad de la autorización preventiva para los actos que exceden el uso ordinario; ambos son comunes y aun cuando el problema de la derivación no es analizado respecto del agua de mar, debe entenderse que si alguno hubiese querido realizar una obra en tal sentido, sería totalmente libre de hacerlo, de tal manera que con mayor razón ocurría aquello cuando se realizaba respecto de los ríos.

Una diferencia más insalvable, parece aquella recordada en D. 39,1,1,17 (Paul., 57 ed.) y D. 39,1,1,18 (Pap., 3 quaest.), según la cual no se puede denunciar la nueva obra, construida en las costas o en el mar, sino sólo obtener caución de daño temido, mientras el mismo remedio sería aceptado, no solamente "damni infecti causa", sino también "iuris publici tuendi" o "iuris nostri conservandi gratia" en el caso de un opus que se construye sobre la ribera del río. Sin embargo, nuestro autor plantea que la diferencia es más aparente que real, pues ella tendría sentido en un ambiente, como el clásico, en el cual se distingue abiertamente entre una y otra forma de denuncia, pero en el siglo VI, los diversos tipos de nuntiatio no sólo se confunden, sino que en cierto modo son absorbidos por la acción de daño temido, no diferenciándose más, para los fines de la ejercitabilidad, entre uno y otro remedio, entre obras ilegítimas y obras legítimas de las cuales se teme el daño. Así, las distinciones que plantea el $\$ 17$ y $\$ 18$, esto es entre río y mar, no tienen motivo de existir en esta última época.

En cuanto a la sustancia, la diferenciación parece basada en el hecho que el tercero no tendría derecho de prohibir aquella obra que se construye sobre el mar o su costa, a diferencia de cuanto acontece en el río, pero ya se ha visto que un permiso preventivo es necesario tanto en un caso como en el otro.

${ }^{43}$ D. 1,8 ; Inst. 2,1 . 
Por el contrario, una verdadera diferencia es la que se refiere a los derechos de los privados sobre la cosa. Mientras en la ripa fluminis y el mismo álveo son los titulares de los predios ribereños, para el mar y sus costas opera el principio contrario, ya que toda cosa que surja en él es del primer ocupante y respecto de la posibilidad de apropiación de las playas y del mar por parte de los propietarios vecinos, ella es rechazada.

Pese a esto no parece que las diferencias aquí marcadas, sean suficientes para entender que los ríos y el mar caen en categorías distintas de cosa, especialmente por el hecho de que tanto en uno como en otro caso el uso es público o común.

d) Resumiendo, independientemente de las afirmaciones textuales, no se puede negar que la distancia entre res publicae y res communes, sea que se entienda incluir entre estas últimas a los ríos o no. Si los ríos ingresan en la primera categoría de cosa e incluso siendo parte de la segunda, es evidente que entre aquella y esta no hay la solución de continuidad necesaria para poder distinguir desde el plano dogmático. Por tanto, no resulta sorprendente que la tendencia a la unificación entre las res communes y las res publicae se manifieste dejando fuera los ríos, a pesar de la enumeración taxativa contenida en Inst. 2,1,1 y D. 1,8,2,1 (Marcian., 3 inst.) ${ }^{44}$.

El gran obstáculo para finalmente entender la sistemática, viene dado por el hecho de que el término "publicus", presenta una oscilación de significado y utilización, que atenta en contra de la fijación de un concepto técnico asociado a él, lo que a su vez explica el constante proceso de interrelación entre las dos categorías de res extra patrimonium humani iuris.

2. Una vez que ha demostrado que en el derecho bizantino, la clasificación tripartita de res extra patrimonium humani iuris no tiene razón de ser, Branca ${ }^{45}$ hace referencia a la situación en el derecho clásico y sintetiza la diferencia entre res communes omnium, res publicae y res universitatis. Particularmente alude a la época severiana, en la que observa una clara diferencia entre las res communes (al menos en lo que se refiere al mar y la costa) y las res publicae, pues sólo estas últimas pertenecen al populus Romanus:

a) El mar y sus costas son de todos, uti singuli. Por el contrario, toda otra cosa de uso común (como los ríos), pertenecen al Estado, pueden ser usadas por los cives y sólo en cuanto mantienen la calidad de tales. Es evidente, por tanto como la simplicidad de las relaciones jurídicas en el campo de las cosas de todos está en un contraste innegable con cuanto se puede observar para las res publicae: allí se trata de regular simplemente el uso de cada uno en relación a la actividad y los intereses de los otros; aquí no basta con aquello, sino que además es necesario guardar las relaciones de los privados con la autoridad.

b) Hay una configuración diversa del usus: toda utilidad que se obtiene del mar o de sus costas, desciende del principio de la pertenencia de él a todos y cada uno y no tiene un límite negativo en el igual derecho del otro: el particular usa

\footnotetext{
${ }^{44}$ RobBe, Ubaldo, cit. (n. 14), p. 152.

${ }^{45}$ Branca, Giuseppe, cit. (n. 41), pp. 205 ss.
} 
y disfruta la cosa como propia, proprio iure. En las res publicae, en cambio, toda facultad de uso y goce nace solamente de la destinación de ella: es verdad que la publicidad de los cursos de agua perenne es reconocida a priori, pero esto en cuanto se atribuyen derechos independientemente de la pertenencia al Estado: vale fijar sólo un criterio seguro (perennidad) para distinguir entre los ríos que pertenecen a los particulares, como dominio privado de los otros, siendo la referencia de algunos juristas al ius gentium, letra muerta. Es evidente que los poderes, de cada uno sobre las res publicae, sólo son reconocidos uti civis: el uso de este es normalmente público, no solamente porque es atribuido a "quis ex populo", sino también porque lo consiente el Estado.

c) Por lo demás, el uso del mar o sus costas es virtualmente ilimitado (en la medida que se respeten los intereses de los otros); en cambio, el uso común de las res publicae, tiene una limitación muy precisa en la titularidad del Estado, que permite la innovación. De hecho, mientras Ulpiano señala la facultad de construir en el mar desde el principio del uso común (en cuanto derecho propio) ${ }^{46}$, no dice lo mismo respecto de los ríos y de las otras res publicae: esto que es del Estado no puede transformarse en una cosa privada, si no es a través de la renuncia genérica o específica de él. En realidad, el mar es una res communis por una norma de derecho natural ${ }^{47}$, que es aceptada fácilmente en cuanto no controvierte el derecho del Estado; pero esto no implica que éste en vista de particulares exigencias de los privados o de su patrimonio, no deba apropiarse pro parte, aunque sin necesidad de transformar la cosa, como en cambio es necesario a todo particular y todo ello en virtud de su poder soberano.

d) De lo dicho no se puede llegar a concluir que el mar o las costas son res in patrimonio alicuius: el derecho de disposición es reconocido al mismo tiempo a cada uno y la cosa sigue siendo de todos, no ingresando a patrimonio alguno. Esta característica deriva de la pertenencia del mar y de sus costas a todos y a cada uno, mientras que en las res publicae deriva del hecho de que ellas son del Estado y están por tanto, fuera del patrimonio de los cives. Es natural, en consecuencia, que no sea prohibida la construcción sobre el mar o sus costas: la autoridad no podría afirmarla sin al mismo tiempo negar el carácter de cosa de todos y de cada uno que tienen las res communes: solamente si se llega a turbar su uso, la intervención es legítima. En las res publicae, en cambio, esto es cosas que no son de ninguno sino del populus, no se reconoce a priori la libertad de construcción de parte de los particulares.

e) Respecto de la autonomía que las res universitatis tienen en relación con las res publicae, ella se justifica desde un aspecto negativo: la cosa que no es de todos los hombres, ni es del Estado, ni tampoco de los particulares, pertenecen a aquellas ciudades que han perdido su independencia originaria y se llaman res universitatis. Un primer carácter diferenciador está constiuido por el hecho que no pueden considerarse del populus Romanus, sino de un conjunto de cives, los que han perdido desde antiguo el poder soberano: de aquí la tendencia, de llamar

\footnotetext{
${ }^{46}$ D. 43,8,3,1 (Ulp., 66 ed.).

${ }^{47}$ D. 1,8,2 pr. (Marcian., 3 inst.).
} 
communes civitatium, más que publicae las cosas de la ciudad. Todavía hay más, pues en realidad no son res publicae todas aquellas sobre las cuales el populus ejercita su poder soberano, sino solamente sobre las cuales él puede ejercer un derecho absoluto y directo, que en cierta medida podríamos llamar dominio. Puesto esto, Branca no ve cómo la exigencia o no del poder soberano en el ente al cual él pertenece debiese convencer a los juristas de dar una u otra calificación a la cosa, cuando este principio de soberanía no tenía ningún valor para finalidad de establecer la pertenencia. Se agrega que la universitas, al menos en los tiempos de $\mathrm{Gayo}^{48}$, es derivada de la reunión de ciudadanos romanos esto es el populus mismo: que los romanos no tengan la idea abstracta de la persona jurídica, entendida como unidad; y que por el contrario consideraran la unión de los individuos que forman la corporación, ya es un hecho probado.

Para Marciano las cosas públicas no son res universitatis y ello trae como consecuencia que, en su concepto, el populus mismo no es técnicamente una universitas: pero además, si el Estado no es una unión atomística de individuos, ni una colectividad organizada (universitas), ¿qué otra cosa puede ser sino persona jurídica en el sentido moderno? Por ello, dice Branca, está bien contrapuesto, a propósito de la summa divisio rerum, los individuos a la universitas-colectividad.

De este modo se justifica la autonomía de las res universitatis que, en cuanto a su régimen no difieren profundamente de las res publicae, distinguiéndose de éstas últimas porque son de un ente que se diferencia de los particulares porque está formado por más individuos y se destaca de la universitas porque es concebido como un todo único diverso de la unión de personas que lo componen: son las cosas del Estado visto como persona jurídica abstracta.

3. Por último, Branca ${ }^{49}$ concluye su discusión en torno a las res extra patrimonium humani iuris, poniendo énfasis en la elaboración jurisprudencial de las mismas en los siguientes términos:

Una vez fijados los caracteres diferenciadores entre las cosas, en base a ellos, la distinción en las tres categorías y sobre todo entre las res publicae y las communes era clara entre los juristas de la época clásica y ello lleva a descartar la autoría de Marciano. Pero esto no significa que las res communes estuvieran perfectamente configuradas y tuvieran autonomía, pues las cosas que estaban en esta categoría, fueron llamadas indistintamente res publicae: no siendo de los particulares ni de los dioses y pudiendo ser usadas por todos, la poca imaginación de los romanos, cuando a estos se le viene encima el asunto de la pertenencia los lleva a generalizar el concepto. De otra parte, esta terminología debió haber sido muy antigua y los juristas de la época, ocupándose para fijar o aclarar el régimen no hacen más que repetirla y adoptarla ampliamente.

Ahora, afinado que la naturaleza pública de los puertos, de los ríos y de las calles, no se funda sobre el principio de la pertenencia al populus, como distinta de la mera soberanía, el concepto de res communes, en contraposición a pública,

\footnotetext{
${ }^{48}$ Gai. 2.1.

${ }^{49}$ Branca, Giuseppe, cit. (n. 41), pp. 216 ss.
} 
no puede ser absoluta: habíamos visto como la presencia del Estado, que en cierto sentido es el propietario, caracteriza inconfundiblemente a las res publicae clásicas. Para los juristas de esta época la libertad de construir en la costa sin la autorización deriva del hecho que la costa no es considerada pertenencia del Estado, pero cae en el imperium de este, por lo que resulta evidente que la falta de libertad en el campo de la aedificatio sobre ríos deriva correlativamente del principio de que estos son más que un objeto sobre los cuales se ejerce la soberanía del populus Romanus, entendiéndose que le pertenecen como propios.

Finalmente, la particular figura de aquellas cosas que se llaman res communes se concretará en el hecho de que ellas no son del populus Romanus, ni de una colectividad organizada. Pero en la antigüedad, cuando se adopta la terminología "populicus- publicus", el Estado no era ciertamente concebido como una persona jurídica: las cosas del populus, son de todos los ciudadanos en una forma muy diversa a la del condominio: cuando se pretende justificar el derecho de transformación (aedificatio) no es necesario configurar las cosas como públicas (especialmente el mar y sus costas), pues basta recurrir al principio de que se trata de una cosa propia, en cuanto communis omnium civium.

Además de esto, cuando Aquilio Gallo ${ }^{50}$ llama "públicas" a las costas, no quiere decir más que son cosas que están fuera del patrimonio de los particulares y en este mismo sentido se puede argumentar el contenido de los siguientes textos: D. 50,16,112 (Iav., 11 ex Cass.): "Litus publicum est eatenus, qua maxime fluctus exaestuat. idemque iuris est in lacu, nisi totus privates est". Tambien D.1,8,10 (Pomp., 6 ex Plaut.) : "Aristo ait, sicut id, quod in mare aedificatum sit. fieret privatum, ita quod mari occupatum sit, fieri publicum".

Tanto Iavoleno como Aristón, entienden que las costas están constituidas por todo cuanto está ocupado por el mar y no son cosas privadas, sino que por el contrario quedan fuera del patrimonio de los particulares: en una contraposición rápida "privatum" no se podía oponer sino al término "publicum", cuando se piensa así, aunque ya estuviere asentado entre los juristas, la primera categoría marcianea no habría sido útil invocarla, dado que "communis" era la palabra que indicaba, en sentido técnico, la res en condominio.

Es mérito de Celso ${ }^{51}$ el asumir una dirección más exacta y en este sentido poco importa si el jurista aparece aislado por cuanto refiere el régimen y la colocación dogmática del litus, considerado como verdadera y propia res publica, pues lo interesante es que se debe a él la clara distinción entre los conceptos de "pertenencia” y de "soberanía” y, correlativamente, la fijación del principio, por el cual las res publicae son tales en cuanto pertenecen, podemos decir, loco dominiii al populus Romanus.

De esta forma, e imbuidos en dicho concepto, no resulta soprendente que Celso configure adecuadamente el régimen del mar de acuerdo a la siguiente lógica: todo el mar es de uso libre de los hombres ("omnibus hominibus"), de manera que la libre aedificatio sobre el él y la adquisición del dominio de ésta,

${ }^{50}$ CiC., Top. 7,32 .

${ }^{51}$ D. 43,8,3 (Cel., 39 dig.). 
se justifican, no con el principio discutible invocado por Neracio (res nullius), sino con el otro del uso común. Vale decir, que comienza a ser tomada una idea nueva, en virtud de la cual la posibilidad de transformar una parte del mar, se explica dado que se trata de un derecho o facultad ejercida sobre una cosa que no es del populus, sino de todos.

En suma, el texto de Celso permite argumentar la tesis de las res publicae sobre la base de la pertenencia al Estado de la cosa misma que son in usu populi; además de servir de base para sostener que el ingreso del aire en aquellas serían la res communes se debe atribuir probablemente a la invocación ("ut aeris") de este jurista. Sin embargo, lo más probable es que Celso no quisiera considerar el aire como una cosa, sino sólo dar a entender que el mar es de todos, de la misma forma de cuanto se dice del aire. El inciso por tanto, no parece sospechoso, a diferencia de aquellos que lo consideran inicuo ${ }^{52}$.

Con los últimos grandes juristas de la época clásica la res communes, como categoría distinta de otras, se imponen y aun cuando falta una formulación exacta, no puede decirse que por ello sea ignorada. D. 18,1,34,1 (Paul., 32 ed.): “Omnium rerum, quas quis habere vel possidere vel persequi potest, venditio recte fit: quas vero natura vel gentium ius vel mores civitatis commercio exuerunt, earum nulla venditio est". D. 18,1,51 (Paul., 21 ed.): "Litora, quae fundo vendito coniuncta sunt, in modum non computantur, quia nullius sunt, sed iure gentium omnibus vacant: nec viae publicae aut loca religiosa vel sacra. itaque ut proficiant venditori, caveri solet, ut viae, item litora et loca publica in modum cedant".

Del primer texto, Branca manifiesta dudas, no porque la opinión según la cual la dicotomía ius naturale-ius gentium sea postclásica lo convence del todo, sino sobre todo, por cuanto se nota una contradicción patente con el contenido del $\$ 51$ : el mismo jurista que conecta al ius gentium la extracomerciabilidad de la costa (\$51), no puede al mismo tiempo, hacer derivar la extracomerciabilidad de las res communes como también de las costas, de la naturaleza como una entidad diversa del derecho de gentes. Pero, presentada esta situación, Branca prefiere la autenticidad del segundo fragmento respecto del primero, en contradicción con Perozzi ${ }^{53}$, quien cree que ambos pasajes están interpolados.

Entonces, si las costas se ponen junto a las vías y a los loca publica, de aquí se puede argumentar, como se ha hecho, que son públicos también en el pensamiento de PAULO, quien vuelve a decir que son igualmente extra commercium, con todos los efectos que tal naturaleza produce en materia de compraventa. Sin embargo, parece curioso el hecho que las costas, en todo el fragmento, no son acompañadas del apelativo "pública" que, en cambio, aparece referido a las vías: esta es una prueba, desde el punto de vista de Branca, que las costas en el concepto de Paulo, no pertenecen a la misma categoría de las res publicae y que las palabras "quia-vacant" son genuinas.

La fijación definitiva de la tricotomía (res communes, res publicae, res universitatis) se da de todos modos en esta época. De hecho, la distinción entre las primeras

\footnotetext{
${ }^{52}$ Perozzi, Silvio, cit. (n. 21), p. 596 n.1.

${ }^{53}$ Ibíd., p. 600.
} 
dos categorías no es ignorada por Ulpiano y esto se prueba por la consideración siguiente: la adquisición del dominio sobre la construcción elevada en el mar y la falta de ejercitibilidad de la operis novi nuntiatio iuris publici ${ }^{54}$; la naturaleza del interdicto útil conferida al ne quid in loco publico fiat, cuando es concedido para el opus in mari ${ }^{55}$; la análoga estructura del otro remedio contemplado en D. 43,12,1,17 (Ulp., 68 ed.); la distinción entre utilidad pública y privada ${ }^{56}$ que no ingresa propiamente en el campo de las res communes; en fin, aquel mismo fenómeno, por el que se distingue, en las res publicae, entre relaciones de cada uno con los particulares, como privados o como ciudadanos y relaciones de cada uno con el Estado, resulta especialmente de la observación de diversos remedios que se relacionan el uno con el otro en la esfera del propio tratamiento ulpianeo.

De hecho, la summa divisio en Ulpiano se desarrolla en términos muy semejantes a la de Gayo en D. 43,1,1 pr. (Ulp., 56 ed.) : "Videamus, de quibus rebus interdicta competent. et sciendum est interdicta aut de divinis rebus aut de humanis competere. divinis, ut de locis sacris vel de locis religiosis. de rebus hominum interdicta redduntur aut de his, quae sunt alicuius, aut de his, quae nullius sunt. quae sunt nullius haec sunt: liberae personae, de quibus exhibendis ducendis interdicta competunt. quae sunt alicuius, haec sun taut publica aut singulorum. publica: de licis publicis, de viis deque fluminibus publicis. quae autem singulorum sunt, aut ad aniversitatem pertinent, ut interdictum quorum bonorum, aut ad singulas res, $u$ test interdictum uti possidetis de itinere actuque".

Si contraponemos las res divinae a las humanae y distinguimos estas últimas en cosas alicuius y nullius, las res alicuius en públicas y privadas (singulorum), resulta como advertíamos previamente que la sistematización ulpianea no se distancia de la gayana: además el texto, largamente sospechoso, es genuino al menos en sus líneas fundamentales, tanto más en cuanto el retorna a la summa divisio (res divinae, res humanae) y aunque no figuran las res communes, no puede argumentarse por ello que el jurista las ignora, de la misma manera que no puede decirse que desconoce las res sanctae, pese a que no las menciona ${ }^{57}$.

Ulpiano se libera de algunas trabas que tenía Gayo: también para él como para Marciano, las cosas públicas no son ni singulorum, ni nullius, sino que pertenecen al Estado como persona (alicuius). Además, al referirse a estas cosas como "res alicuius" en vez de "res in bonis alicuius", supera el defecto de la construcción gayana: también los bienes demaniales del populus, por no estar en el patrimonio (in bonis) de este, eran de todos modos del populus. En el pensamiento de Ulpiano, la clasificación de las cosas se basa en el criterio efectivo de la pertenencia y en vista de este criterio se dice que el mar es de todos. Sin embargo, aquello no excluye que, cuando el mismo jurista precisa: "loca enim publica utique privatorum usibus

${ }^{54}$ D. 39,1,1,17-18 (Ulp., 52 ad ed.).

${ }^{55}$ D. 43,8,2,8 (Ulp., 68 ed.).

${ }^{56}$ D. 48,8,2,2 (Ulp., 68 ed.).

${ }^{57}$ Incluso no se puede señalar que la clasificación es incompleta, puesto que ella tiende a dirimir la situación de los interdictos y no de las cosas. Mirado desde este punto de vista, la ausencia de las res communes omnium se justifica desde el momento en que ellas no tienen una protección interdictal específica. 
deserviunt, iure scilicet civitatis, non quasi propria cuiusque" 58 , la antítesis valga precisamente en referencia al mar y sus costas.

Por lo tanto, no parece inverosímil pensar que Ulpiano aisladamente, en el seno de las cosas públicas, distinguiera las res univesitatis marcianeas, esto es, la

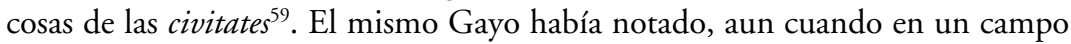
específico que "publica appellatio in compliribus causis ad populum Romanum respicito: civitates enim privatorum loco" ${ }^{60}$, afirmación de la cual se puede deducir que la civitas no es siempre entendida como un privado. Sin perjuicio de lo anterior, no se puede afirmar que Gayo conscientemente se mueva en la misma corriente de ideas que hacía preferir el término "publicus" frente a "communis", pues todavía establece una cierta distancia entre "universitas populi" y "universitas civitatis".

En esta misma línea, Ulpiano nos presenta dos textos notables. Primeramente, en D. 50,16,15 (Ulp., 10 ed.) : "Bona civitatis abusive publica dicta sunt: sola enim ea publica sunt, quae populi Romani sunt”. Luego en D. 50,16,17 pr.-1(Ulp., 10 ed.) : "Inter publica habemus non sacra nec quae publicis usibus destinata sunt: sed si qua sunt civitatium velut bona. sed peculia servorum civitatium procul dubio publica habentur. (1) 'Publica' vectigalia intelligere debemus, ex quibus vectigal fiscus capit: quae est vectigal portus vel venalium rerum, item salinarum et metallorum et picariarum".

El jurista evidentemente se ocupa de las cosas patrimoniales, como indica el término "bona" en ambos fragmentos y vale decir que la materia precisa que comenta (representación procesal de los municipes), hace entender que el término "publicus" se refiere, en este caso, sólo a los bienes municipales.

En definitiva, Ulpiano no tuvo la necesaria firmeza para imponer la tercera categoría marcianea (res universitatis), pero da un gran paso en beneficio de ésta: se ha batido en contra del término "publicus" respecto de las cosas de la ciudad, demostrando estar en un clima que era ya maduro para la consagración de aquella tercera categoría de cosas. Esto parece que basta para rechazar la idea de Perozzi ${ }^{61}$, el cual atribuye a los bizantinos la creación de las res universitatis como distintas de las cosas públicas. Veamos las fuentes:

i) D. 1,8,2 (Marcian., 3 inst.) : "Quaedam naturali iure communia sunt omnium, quaedam universitatis, quaedam nullius, pleraque singulorum quae variis ex causis cuique adquiruntur. et quidem naturali iure omnium comuna sunt illa: aer, aqua profluens, et mare, et per hoc litora maris".

ii) D. 1,8,4,1 (Marcian., 3 inst.) : "Sed flumina paene omnia et portus publica sunt".

iii) D. 1,8,6,1 (Marcian., 3 inst.) : “Universitatis sunt, non singulorum veluti quae in civitatibus sunt theatra et stadia et similia et si qua alia sunt communia civitatium. Ideoque nec servus communis civitatis singulorum pro parte intellegitur, sed universitatis et ideo tam contra civem quam pro eo posse servum civitatis tirtra civem

\footnotetext{
${ }^{58}$ D. 43,8,2,2 (Ulp., 68 ed.).

${ }^{59}$ Bonfante, Pietro, Corso di Diritto Romano. La proprietà, cit. (n. 26), p. 89.

${ }^{60}$ D. 50,16,16 (Gai., 3 ed. prov.).

${ }^{61}$ Perozzi, Silvio, cit. (n. 21), p. 597 n. 1.
} 
quam pro eo posse servum civitatis torqueri divi fratres rescripserunt. Ideo et libertus civitatis non habet necesse veniam edicti petere, si vocet in ius aliquem ex civibus".

Si Marciano, en estos fragmentos, hubiese incorporado conceptos nuevos, se habría podido también discutir la autenticidad de los mismos. Pero lo que ocurre es absolutamente lo contrario, dado que los principios en los cuales se fundamenta la clasificación, ya se han formado: las res communes omnium y las res universitatis estaban ya diferenciadas, más o menos explícitamente con Ulpiano y en cierto sentido en otros juristas. La tendencia a llamar nullius solamente las res divini iuris no era extraña del todo a Gayo, como lo demuestra el hecho de que señale que las res humani iuris son normalmente alicuis $^{62}$. En fin, nada de extraño es que en la misma clasificación marcianea no figuren como distintas de las res singulorum, aquellas cosas que actualmente no son de nadie, pero siendo susceptible de apropiación no entraban en la summa divisio más antigua y que, cuando pertenecen a todos, no pueden ser objeto de valoración jurídica. En suma, Marciano, está bastante lejos de crear algo, y sigue, en sustancia, el pensamiento de Ulpiano.

Si agregamos a todo esto, el hecho de que tricotomía res communes, res publicae y res universitatis no tiene sentido en el derecho bizantino, por lo que no existe necesidad de que haya sido creada en dicha época, ello lleva a dar por superada la tesis de Perozzi en dicho sentido ${ }^{63}$, pues sostenía que los textos genuinos no conocieron sino las res publicae.

Por todo esto, sustancialmente Marciano señala que la mayor parte de las cosas pertenecen o pueden pertenecer a los privados; las otras no son susceptibles de pertenencia: algunas de ellas no son de nadie; otras pertenecen a todos. Estas últimas o son de una colectividad organizada, o del Estado concebido como una persona abstracta, o de una gran colectividad organizada jurídicamente: las recién mencionadas, en cuanto falta tal organización y en cuanto era absurdo que el Estado destinase alguna cosa al uso de todos los hombres, genera el origen de las categoría de res communes omnium como de una derivación del ius naturale.

\section{La ARGUMENTACión DE SCHERILlo}

También Scherillo ${ }^{64}$, defiende la categoría de las res communes omnium para el derecho clásico, admitiendo que ahí se produjo un desarrollo jurisprudencial delineado de la siguiente manera: al parecer de nuestro autor, no puede negarse que en la sistematización de la categoría debe atribuírsele una posición relevante a Marciano: probablemente es obra de él la inclusión de esta en la calificación de las cosas, como así también la fijación del elenco de las comprendidas en ella; pero lo cierto es que el maestro tardo-clásico no hace más que sistematizar un orden que se había desarrollado jurisprudencialmente desde hacía un siglo en orden a este tipo de cosas:

${ }^{62}$ Gai. 2,9.

${ }^{63}$ Perozzi, Silvio, cit. (n. 21), pp. 596 ss.

${ }^{64}$ Scherillo, Gaetano, Lezioni di diritto romano. Le cose (Milano, Giuffrè, 1945), pp. 69 ss. 
a) En los textos referidos ${ }^{65}$, el concepto de res communes omnium está claramente expresado y los ejemplos son aquellos que utiliza Marciano: el mar, sus costas, el aire y el agua corriente. Esto demuestra que la categoría estaba viva en la tradición filosófica-literaria.

b) De las cuatro cosas mencionadas por Marciano, en los textos de los otros juristas se recuerdan dos: el mar y sus costas. El aire es mencionado sólo en dos textos $^{66}$; situación que se repite en el caso del aqua profluens ${ }^{67}$, pero no con un significado técnico; al punto que es incierto y disputado qué cosa realmente significa, si el agua de lluvia, la de los ríos o la que escurre a través de torrentes abiertos. Sin duda, como se verá oportunamente, la inserción del aire y del aqua profluens en el elenco de las res communes omnium es obra personal de Marciano.

c) De mayor peso es la constatación de que la categoría de las res communes omnium, no aparece en la clasificación gayana de las cosas, ni en la de los interdictos de Ulpiano y Paulo ${ }^{68}$ modelado sobre la clasificación de las cosas: junto con las res divini iuris y las pertenecientes a los privados, sólo son recordadas las res publicae. Pero la verdad es que esta clasificación es bastante antigua, por lo que no debe extrañar que las res communes omnium no estén presente en ella, al menos con autonomía. Esta situación es corroborada por el hecho de que esa misma categoría no está entre las cosas extra commercium o extra patrimonium, mientras que sí figuran las res divini iuris y las res publicae. Los ejemplos son numerosos: Inst. 2,20,4; Inst. 3,19,2; D. 18,1,6 pr. (Pomp., 6 Sab.); D. 18,1,62,1 (Mod., 5 reg.); D. 18,1,72,1 (Pap., 10 quaest.); D. 30,39,8-10 (Ulp., 21 Sab.); D. 41,3,9 (Gai., 4 ed. prov.); D. 45,1,83,5 (Paul., 72 ed.).

De aquí deriva la idea de que originalmente la jurisprudencia conocía solo la categoría de las res publicae, que comprendía todas las cosas que no eran divini iuris y tampoco pertenecían a los privados. Tal categoría, es objeto de una intensa elaboración por parte de los juristas y, por tanto, de un cierto momento se comienza a distinguir contraponiéndose a las res in usu populi aquellas in pecunia (o in patrimonio) populi ${ }^{69}$; de esta misma forma, se tiende a reagrupar las cosas cuya publicidad dependía de una derivación del ius gentium, las res publicae iuris gentium $^{70}$; finalmente, así también se inicia el proceso de diferenciación de las cosas del Estado y aquellas de la ciudad ${ }^{71}$, para la que se crea una denominación especial: res universitatis.

Así, no es extraño que la jurisprudencia, o al menos algunos juristas, teniendo en cuenta la peculariedad del régimen del mar y sus costas, hagan el contraste de

${ }^{65}$ Plaut., Rudens 4,3,36; 4,3,42; Cic., Pro Roscio, 26,72; Cic., De off., 3,16,52; Ovid., Metam., 6,349; SEn., De benef., 4,28.

${ }^{66}$ D. 43,8,3,1 (Cel., 39 dig.) y D. 47,10,13,7 (Ulp., 57 ed.).

${ }^{67}$ D. 39,3,1,22 (Ulp., 53 ed.) y CI. 3,34,6-7.

${ }^{68}$ D. 43,1,1 pr. (Ulp., 67 ed.); D. 43,1,2,1 (Paul., 63 ed.).

${ }^{69}$ D. 18,1,6 pr. (Pomp., 6 Sab.); D. 18,1,62,1 (Mod., 5 reg.); D. 18,1,72,1 (Pap., 10 quaest.); D. 30,39,8-10 (Ulp., 21 Sab.); Inst. 3,19,2; Inst., 2,20,4.

${ }^{70}$ D. $1,8,5$ pr. (Gai., 2 rer. cott.); D. 18,1,34,1 (Paul., 33 ed.); D. 41,3,35 pr. (Iul., 3 Urs.).

${ }^{71}$ D. 41,3,9 (Gai., 4 ed. prov.); D. 50,16,15 (Ulp., 10 ed.); D. 50,16,16 (Gai., 3 ed. prov.). 
estas cosas con las otras que también recibían la denominación de públicas. Es necesario tener presente este trabajo, porque explica la oscilación de los textos, tanto en la nomenclatura como en el régimen jurídico.

El punto de partida, tanto para el mar como para las costas, es el de cosa pública y ello puede probarse a través del análisis de diversos textos, independientemente de las consideraciones hasta ahora vistas: para las costas tenemos ante todo un testimonio directo de aquella opinión, pacífica en la jurisprudencia republicana ${ }^{72}$, y también un siglo más tarde cuando Iavoleno se refiere al asunto ${ }^{73}$ : el hallarse el pasaje en una obra ex Cassio hace suponer que tal era también el pensamiento de dicho jurista, por lo que de ser así tendríamos una tradición constante desde los veteres hasta los grandes juristas de la escuela sabiniana. En lo que se refiere al mar, no existen testimonios directos de la jurisprudencia republicana, pero su condición de público resulta clara, al menos hacia la época del emperador Trajano, como apoarece en D. 1,8,10 (Pomp., 6 ex Plaut.): "Aristo ait, sicut id, quod in mare aedificatum sit, fierit privatum, ita quod mari occupatum sit, fieri publicum".

En este texto comienza a distinguirse el régimen particular del mar en lo que dice relación con la construcción hecha en él (libertad para todos de construir y adquisición de la propiedad de lo construido), pero además se afirma su carácter público sin que existan discusiones al respecto.

En la afirmación de que tanto el mar como sus costas son públicos, hay aparejado un régimen específico: libre uso en los límites de la destinación propia de la cosa, lo que explica la libertad de caminar y secar las redes para las $\operatorname{costas}^{74}$; y para el mar la pesca y la navegación ${ }^{75}$. Del primero de los dos textos resulta que el parangón con el uso de las otras cosas públicas era común a la jurisprudencia ("et plerique"): el paralelo significa identidad de régimen, esto es negación, en caso de turbación del interdicto ne quid in loco publico fiat, faltando un facere y, en cambio la tutela del uso de parte de los privados mediante la actio iniuriarum. Todo ello no es una innovación de Ulpiano, sino de principios derivados de la jurisprudencia anterior.

Si respecto del uso del mar y de las costas la regla era la libertad a absoluta, pese a ello el Estado podía conceder a cualquiera el ejercicio exclusivo de esta facultad. De hecho, para la pesca esto es documentado en monumentos epigráficos y resulta además citado en D. 47,10,13,7 (Ulp., 57 ed.). El interdicto concedido por los veteres (se entiende la jurisprudencia republicana) al concesionario del derecho exclusivo de pesca era indudablemente, como resulta claro de las palabras "quo minus conductione sua fruatur", el interdicto de loco publico fruendo ${ }^{76}$. De esto se sigue que si los veteres no veían dificultad en conceder el interdicto de loco publico fruendo, entendían evidentemente que el mar era público ${ }^{77}$.

Sin embargo, podemos apreciar que existen dudas en torno a la calificación

${ }^{72}$ Cic., Top., 7,32.

${ }^{73}$ D. 50,16,112 (Iav., 11 ex Cass.).

${ }^{74}$ D. 1,8,4 pr. (Marcian., 3 inst.); Inst, 2,1,5.

${ }^{75}$ D. 43,8,2,9 (Ulp., 58 ed.); D. 47,10,7,13 (Ulp., 57 ed.).

${ }^{76}$ D. 43,9,1 pr. (Ulp., 68 ed.).

${ }^{77}$ Bonfante, Pietro, Corso di Diritto Romano. La proprietà, cit. (n. 26), p. 62. 
$\mathrm{y}$, por tanto, al régimen jurídico del mar y sus costas, lo que queda en evidencia del análisis de los siguientes textos:

D. 41,1,14 (Nerat., 5 membr.) : "Quod in litore quis aedificaverit, eius erit: nam litora publica non ita sunt, ut ea, quae in patrimonio sunt populi, sed ut ea, quae primum a natura prodita sunt et nullius adhue dominium pervenerunt: nec dissimilis condicio eorum est, atque piscium et ferarum, quae simul atque adprehensae sunt, sine dubio eius, in cuis potestatem pervenerunt, dominio funt. (1) Illud videndum est, sublato aedificio, quod in litore positum erat, cuius condicionis is locus sit, hoc est utrum meneat eius cuius fuit aedificium, an rursus in pristinam causam reccidit perindeque publicus sit, ac si numquam in eo aedificatum fuisset. quod proprius est, ut existimari debeat, si modo recipit pristinam litoris speciem".

D. 43,8,3 pr.-1 (Cel., 39 dig.) : "Litora, in quae populus Romanus imperium habet. (1) Populi Romani esse arbitror: Maris communem usum omnibus hominibus, ut aeris, iactasque in id pilas eius esse qui iecerit: sed id concedendum non esse, si deterior litoris marisve usus eo modo futurus sit".

Celso, a imitación de Aristón, admite que la construcción hecha sobre el mar sea propiedad del constructor, pero para justificar el principio no recurre a la cualidad de res nullius del mar, sino a la circunstancia de que el uso del mar corresponde a todos los hombres y como consecuencia de ello, nadie puede apropiarse de una porción de él. De la frase delineada en el $\$ 1$ ("maris communen usum omnibus ut aeris") podría deducirse que Celso conocía la categoría de las res communes omnium y que él incluye el aire en el elenco respectivo. Este último punto, en todo caso es dudoso: Celso refiere el aire a modo de ejemplo, para decir que todos se pueden servir del mar como se sirven del aire, pero no dice que el aire sea una cosa, ni que pertenezca a dicha categoría.

Se debe tener presente que estos principios relativos a la construcción en el mar y sus costas se vienen afirmando ahora por primera vez, pues la regla general contraria había sido formulada por Labeón en D. 41,1,65,4 (Lab., 6 pith. Paul. epit): "Si id quiod in publico innatum aut aedificatum est, publicum est, insula quoque, quae in flumine publico nata est, publica esse debet".

Además, la adquisición de la propiedad de lo construido en el mar o sus costas es afirmado también por Pomponio en otros textos, uno de los cuales ${ }^{78}$, ya se había examinado para comprobar el originario carácter público del mar. Pero se puede adicionar el contenido en D. 41,1,30,4 (Pomp., 39 Sab.) donde nuestro jurista adhiere a la opinión de Neracio, adquiriendo la propiedad basado en el hecho de que el mar es res nullius.

Por su parte de las costas, Pomponio se ocupa expresamente en otro sentido en D. 41,1,50 (Pomp., 6 ex Plaut.): "Quamvis quod in litore publico vel in mari exstruxerimus, nostrum fiat, tamen decretum praetoris adhibendum est, ut id facere liceat: immo etiam manu prohibendus est, si cum incommodo ceterorum id faciat: nam civilem eum actionem de faceindo nullam habere non dubito".

El texto, reafirma el principio de la adquisición del dominio de la construcción y cualifica como pública las costas: para la licitud de la realización de las obras

${ }^{78}$ D. $1,8,10$ (Pomp., 6 ex Plaut.). 
parece, sin embargo, requerir concesión por parte de la autoridad. El texto está seguramente modificado, como lo demuestra el repentino cambio de persona en los verbos (de la primera en plural a la tercera en singular).

El pensamiento de Celso en orden al mar, esto es el uso libre a todos los hombres, no parece aislado: otros juristas también hacen una construcción en torno a un grupo de cosas públicas, las res publicae iuris gentium, aquellas en que el carácter de público deriva de un precepto del ius gentium (entendido como un derecho fundado sobre la naturalis ratio, observado, en consecuencia, igualmente para todos los pueblos) que asegura la destinación al uso común. Este grupo comprende los ríos públicos, la ribera de los ríos (limitadamente al uso), el mar y sus costas.

Este mismo razonamiento lo podemos encontrar en otros juristas, como se ve en D. 43,8,4 (Scaev., 5 resp.): "Respondit in litore iure gentium aedificare licere, nisi usus publicus impediretur:".

No obstante lo reducido de la sententia, no se puede dudar que Scaevola adscribiese las costas del mar a las cosas públicas iuris gentium, y aun cuando de la adquisición del dominio de la construcción el texto nada dice, pero a favor de que él lo admitiese se puede argumentar el contenido de otro texto proveniente del mismo jurista, como es D. 19,1,52,3 (Scaev., 7 dig.): "Ante domum mari iunctam molibus iactis ripam constituit et uti ab eo possessa domus fuit, Gaio Seio vendidit: quaero, an ripa, quae ab auctore domui coniuncta erat, ad emptorem quoque iure emptionis pertineat. respondit eodem iure fore venditam domum, quo fuisset prisuquam veniret".

En verdad el responsum es ambiguo, y se debe reconocer que no es incompatible con la solución opuesta, pero se puede indicar que la solución afirmativa está supuesta en la demanda del postulante.

El grupo de las cosas públicas iuris gentium y con mención explícita a las costas y a los ríos, también aparece en Papiniano, como se ve en D. 41,3,45 pr. (Pap., 10 resp.): "Praescriptio longae possessionis ad optime nda loca iuris gentium publica concedi non solet. quod ita procedit, si quis, aedificio funditus diruto quod in litore posuerat (forte quod aut deposuerat aut dereliquerat aedificium), alterius postea eodem loco extructo, occupantis datam exceptionem opponat, vel si quis, quod in fuminis publici deverticulo solus pluribus annis piscatus sit, alterum eodem iure prohibeat".

El jurista autor de la sententia, admite la libertad de construcción sobre las costas, pero excluye la aplicación de la longi temporis praescriptio. Sin embargo, teniendo presente que en el derecho clásico ésta no era una institución de carácter adquisitivo del dominio, sino un medio procesal de tutela de la situación de hecho, no se puede argumentar que Papiniano negase la adquisición de la propiedad.

En fin, el grupo de las cosas públicas iuris gentium, es conocido por Paulo, lo que se puede deducir de dos textos. Uno es D. 18,1,34,1 (Paul., 33 ad ed.) : "Omnium rerum, quas quis habere vel possidere vel persequi potest, venditio recte fit: quas vero natura vel gentium ius vel mores civitatis commercio exuerunt, earum nulla venditio est". El otro es D. 18,1,51 (Paul., 21 ed.): "Litora, quae fundo vendito coniuncta sunt, in modum non computantur, quia nullius sunt, sed iure gentium 
omnibus vacant: nec viae publicae aut loca religiosa vel sacra. itaque ut proficiant venditori, caveri solet, ut viae, item litora et loca publica in modum cedant". Además, indirectamente también se puede traer a colación D. 41,1,65,1 (Lab., 6 pith. Paul. epit): "Si qua insula in flumine propia tua est, nihil in ea publici est. Paulus: immo in eo genere insularum ripae flumini et litora mari proxima publica sunt, non secus atque in continendi agri idem iuris est".

El texto está indudablemente manipulado, pero la mención de las costas no puede ser de los compiladores, que no lo consideran público, sino común.

Del análisis realizado resulta además que en la jurisprudencia de la época adrianea y posterior la opinión dominante se orientaba hacia la existencia de un grupo de res publicae iuris gentium, comprendiendo los ríos, el mar y sus costas. Característica de este grupo es el uso libre para todos (todos los hombres, porque la publicidad deriva del ius gentium) y ello comprendía la libetad de construir. Cuanto más en la adquisición del dominio de la construcción, la jurisprudencia se divide: excluida por Gayo y Papiniano, es probablemente admitida por Scaevola y seguramente por Paulo.

Una posición diversa asume Ulpiano, especialmente por el punto de vista de la presentación del problema, él parece más cercano al pensamiento de Neracio y de Celso, que no a sus inmediatos predecesores, pero en lo que se refiere a la posibilidad de ejercicio de la operis novi nuntiatio, contrapone netamente el mar y sus costas a las cosas públicas ${ }^{79}$. Así, mientras es admitida la operis novi nuntiatio iuris publici tuendi causa para las obras construidas en los ríos públicos o sobre la riberas de éstos, es excluída el ("nullo iure prohibet") para las obras construidas en el mar o sus costas.

Si respecto a las cosas públicas todos los ciudadanos tienen derecho de ejercer la operis novi nuntiatio, mientras respecto al mar y sus costas tal derecho no lo tiene ninguno, ello no significa que el mar y sus costas en el pensamiento de Ulpiano no tenían el carácter de públicos. Dicho esto, la referencia al ius gentium del $\$ 18$ no puede entenderse como una alusión al grupo de las cosas públicas iuris gentium que Ulpiano indudablemente no reconoce porque no lo refiere en otros lugares, sino que solamente afirmar el principio, en base a una norma del ius gentium, se adquiere la propiedad del edificio y del suelo.

A la misma conclusión se arriba argumentando con D. 43,8,2,8 (Ulp., 68 ad ed.): "Adversus eum, qui molem in mare proiecit, interdictum utile competit ei, cui forte haec res nociturna sit: si autem nemo damnum sentit, tuendus est is, qui in litore aedificat vel molem in mare iacit".

Contra la construcción en el mar o sus costas, si alguien puede llegar a sufrir un daño específico, se le concede el interdicto ne quid in loco publico fiat, pero por vía útil. De ello se deduce que el mar y sus costas no eran propiamente considerados como lugares públicos, pues de lo contrario no se ejercería el interdicto por vía útil, sino directamente.

Aún más, Ulpiano recoge también el pensamiento de Celso, en el sentido de que el mar es común a todos los hombres, afirmación que se encuentra en dos

${ }^{79}$ D. 39,1,1 (Ulp., 52 ed.). 
textos. D. 47,10,13,7 (Ulp., 57 ed.): “Convicium non tantum praesenti, verum absenti quoque fieri posse Labeo scribit. proinde si quis ad domum tuam venerit te absente, convicium factum esse dicitur. idem et si ad stationem vel tabernam ventum sit, probari oportere"; y D. 8,4,13 pr. (Ulp., 6 opin.): "Venditor fundi Geroniani fundo Botriano, quem retinebat, legem dederat, ne contra eum piscatio thynaria exerceatur. quamvis mari, quod natura ómnibus patet, servitus imponi privata lege non potest, quia tamen bona fides contractus legem servari venditionis exposcit, personae possidentium aut in ius eorum suecedentium per stipulationis vel venditionis legis obligantur".

Ulpiano no se limita a decir, como Celso, que el uso del mar es común a todos los hombres, sino que en el primer texto indica que el mar pertenece a todos, tal como el aire: por esto, de frente a los textos de Ulpiano, no es sostenible la interpretación propuesta para el texto de Celso; ya que el primer jurista mencionado, efectivamente reconoce un grupo de cosas comunes a todos los hombres y en los que se comprende también el aire.

Entonces, Ulpiano, sustancialmente conoce las res communes omnium y él incluye en dicha categoría casi todas aquellas cosas que comprendía Marciano. En la clasificación de los interdictos, modelada sobre la de las $\cos ^{80}{ }^{80}$, que sigue siendo la tradicional, no son colocadas las res communes omnium. Además, en su libro son evidentes las trazas del régimen originario del mar y sus costas, igual a aquellas de las otras cosas públicas. En fin, Ulpiano habla del uso común también para los ríos y las vías, que en un texto son puestas al lado de las costas y de $\operatorname{lmar}^{81}$.

Marciano, al final de la evolución no hace más que formular expresamente el pensamiento de Ulpiano, que no era del todo claro, pero que estaba ya presente en Neracio y Celso. Entendiendo proponer una clasificación de las cosas más exacta que la tradicional, termina por separar de las cosas públicas de aquellas de la ciudad (res universitatis), moviendo el mar y sus costas hacia una categoría propia, a la que le da un nombre, res communes omnium, que recuerda cuanto Ulpiano y Celso decían del mar ("mare commune omnium est"). También la inclusión del aire en la categoría deriva evidentemente del parangón de ella con el mar, realizada por Celso y por Ulpiano; en cambio, la inclusión del aqua profluens no parece tener precedentes en la jurisprudencia y sería una obra personal de Marciano y, al mismo tiempo, no deberían existir dudas que su inclusión depende de la tradición filosófica-literaria.

De todos modos la formulación de las res communes omnium como categoría autónoma muestra una evolución jurisprudencial que primero se encuentra en el ámbito literario.

En efecto, al colocar en un grupo autónomo al mar y sus costas puede ser en cierto modo justificado por la peculariedad del régimen de ellos y que en sustancia se reduce a lo siguiente:

i) La libertad de construcción sobre las costas y el mar, con adquisición de

${ }^{80}$ D. 43,1,1 pr. (Ulp., 67 ed.).

${ }^{81}$ D. 39,2,24 pr. (Ulp., 81 ed.). 
la propiedad de la misma y la consiguiente exclusión de la operis novi nuntiatio iuris publici tuendi causa.

ii) Adquisición de la propiedad por inventio de los objetos hallados sobre las costas. De los otros lugares públicos nada se dice ${ }^{82}$.

iii) Adquisición por ocupatio de la insula in mari nata ${ }^{83}$; mientras que la isla nacida en un río público, era pública ${ }^{84}$.

En cuanto al aire no se puede hablar de peculiaridades respecto de su régimen jurídico, porque los textos ignoran tal régimen: el aire no está regulado por el derecho, esto es, no se trata de una cosa desde el punto de vista jurídico; y esta observación es suficiente para hacer caer toda la argumentación que hacen los defensores de las res communes omnium: que se diga que el mar se puede usar igualmente que el aire, sólo implica decir que no se puede impedir su uso, pero no refiere que tiene la categoría de cosa.

En lo que se refiere al aqua profluens, esto es, literalmente el agua corriente, en abstracto no vale considerarla como cosa distinta del curso de agua grande o pequeño, perenne o no del cual forma parte; pero es necesario ver si el régimen concreto responde o no a esta concepción teórica. La respuesta no puede ser negativa: el agua es pública o privada según sea público o privado el curso del cual forma parte. Y también la libertad de su uso depende de tal condición: el uso será libre si el curso es público, mientras no lo será si el curso es privado. La libertad para todos del uso del agua en las fuentes literarias responde a un principio social y no jurídico. Por tanto, considerando el aqua profluens como cosa en sí, Marciano ha confundido el punto de vista social con el jurídico. La prueba de todo lo que se ha dicho se encuentra en sus propias Institutas: estando en las condiciones según las cuales se han mantenido en la compilación, él incluía el aire y el aqua profluens en el elenco de las res communes omnium, pero en cuanto a su régimen jurídico, sólo ilustraba respecto del mar y sus costas, del aire y el aqua profluens nada dice.

Justiniano ha recogido de las Institutiones de Marciano la categoría de las res communes omnium y las ha colocado tanto en sus propias Institutas como en el Digesto. Pero en cuanto al valor práctico de la categoría, pero respecto del aire y el aqua profluens nada dice. La importancia entonces es meramente teórica.

\section{NUESTRA POSICIÓN SOBRE LAS RES COMMUNES OMNIUM}

\section{La situación en el periodo clásico: pleno reconocimiento de la categoría.}

Pensamos que la referencia hecha en los números anteriores no sólo era absolutamente necesaria, sino también demostrativa de las controversias que ha originado la categoría de las res communes omnium, pues de la simple lectura de lo previamente expuesto, queda de manifiesto el amplio abanico de posiciones que ha tomado la romanística en lo que dice relación con ellas ${ }^{85}$. Así podemos observar

\footnotetext{
${ }^{82}$ Inst. 2,1,18; D. 41,2,1,1 (Paul., 54 ed.).

${ }^{83}$ D. 41,1,7,3 (Gai., 2 rer cott.); D. 41,2,1,1 (Paul., 54 ed.).

${ }^{84}$ D. 41,1,65,4 (Lab., 6 pith. Paul. epit.).

${ }^{85}$ No queremos dejar pasar la oportunidad de manifestar la importancia, más bien histórica,
} 
autores para los cuales la categoría sería del todo extraña al derecho clásico y sólo obedecería a criterios bizantinos o justinianeos; otros que la identifican exclusivamente con la figura de Marciano y, por último, aquellos que la consideran una creación de la jurisprudencia clásica.

Frente a esta amplitud de criterios, teorías y argumentaciones, es bastante dificil plantear puntos de vista novedosos o inexplorados. Por esto y sin perjuicio de que haremos las precisiones del caso cuando ello corresponda, nos parece estar más cercanos a la tesis de Branca y Scherillo, en lo que dice relación con la autenticidad y validez de la categoría de res communes omnium, que de aquellos otros que propugnan la tesis contraria. Esto deriva, particularmente del enfoque metodológico, en especial del primero de los autores citados, dado que parece razonable mirar el asunto desde la siguiente óptica: si existen tres categorías de res extra patrimonium humani iuris, paralelamente deben existir tres régimenes jurídicos correpondientes, pues de no ser así la diferenciación no tendría sentido. Por otro lado, adicionamos nosostros, la naturaleza y el fundamento del uso común en uno y otro caso también es diverso.

Evidentemente, esto nos lleva, porque de otra forma seríamos inconsecuentes, a tomar como propia una premisa básica de la argumentación de Branca: la tricotomía res communes omnium, res publicae, res universitatis, no tiene cabida en el derecho justinianeo, precisamente porque esta diversidad de régimenes es inexistente. Ello trae aparejado una consecuencia que resulta ser relevante al momento de valorar y ponderar sus apreciaciones, pues el camino que recorre es el inverso al que resultaría de cierta manera obvio: el autor previamente mencionado no reconstruye el régimen más antiguo para llegar en último término al más moderno (Corpus Iuris), sino que por el contrario, refiere esté último para poder reconstruir el primero ${ }^{86}$.

Sin ánimo de volver detalladamente sobre las apreciaciones de Branca, podemos recordar que nuestro autor demuestra la falta de diversidad de régimen entre las supuestas "clases" de res publicae, argumentando que respecto de todas ellas, tenemos un régimen en el que existe libre uso para todos y donde la exigencia de un permiso o autorización previa, viene sólo dada en la medida que aquel uso que se pretenda vaya más allá del ordinariamente aceptado. En esta misma línea se puede añadir la carencia de mención de las res universitatis, por ejemplo, a propósito de los interdictos ne quid in loco publico fiat y de loco publico fruendo,

que tiene en este sentido una pequeña obra de Pernice, tal vez olvidada, pero que claramente da cuenta de los conflictos suscitados a propósito de este tema. No hemos reproducido la opinión de este gran romanista, pues no tuvo mayor eco en la romanística y además, sustancialmente coincide con lo manifestado por Bonfante. Véase PERNICE, Alfred, Die fogenannten res communes omnium (Berlín, Berlag von \& M. Müller, 1900).

${ }^{86}$ Por esta misma razón, no nos parece aceptable la crítica de Robbe, en el sentido de que para demostrar la inexistencia de una situación en determinada época, primero se debe demostrar la existencia de la misma en una época anterior. Por lo demás, este autor no hace más que argumentar lo mismo que en su oportunidad realizó Grosso, Giuseppe, Rec. a Branca. Le cose extra patrimonium humani iuris, en SDHI., 8 (1942), pp. 163 ss. Véase RobBE, Ubaldo, cit. (n. 14), p. 216. 
que no puede interpretarse más que como una aceptación del mismo tratamiento jurídico para ambos tipos de cosas.

Siguiendo esta misma explicación, la situación en el periodo clásico es absolutamente distinta, pues los juristas de aquella época diferenciaban entre las categorías de res communes omnium, res univerisitatis y res publicae, particularmente en lo que dice al respectivo régimen jurídico de cada una de ellas y además, agregamos nosotros, en el criterio que se encuentra detrás de la calificación de las cosas en una u otra categoría. Por lo demás, en este punto debemos hacer algunas precisiones, pues tal como indicábamos en su oportunidad, el discurso de los romanistas que han estudiado el tema, y Branca no escapa a ello, se encuentra contaminado, por dos factores: la falta de un concepto técnico de res y la presencia de la figura del Estado, configurado en los mismos términos que para el derecho moderno. Efectivamente, Branca dice que una de las diferencias entre estas cosas viene dada por el hecho de la "pertenencia al Estado", opinión con la que nosotros discrepamos fuertemente y por esto, aunque tomamos las conclusiones básicas de este autor, llegamos a ellas por un camino un tanto diverso. Así, respecto de la categoría de las res communes omnium, que es aquello que nos interesa principalmente podemos decir lo siguiente:

a) Indudablemente, el origen de la categoría como tal, no puede desvincularse del régimen jurídico al que se encuentra sometido el mar y sus costas, por lo que debemos iniciar en este punto la discusión. Y a propósito de ella, conceder que la calificación original de estas dos cosas es la de res publica.

b) Todavía más, el mar y sus costas son las únicas cosas incluídas en el elenco de res communes omnium dado a conocer por Marciano, que son tratadas de manera específica por otros juristas ${ }^{87}$.

c) La particularidad viene dada porque tanto el mar como sus costas pueden ser utilizados por cualquiera y, en principio, sin limitaciones, de forma tal que jurídicamente no se puede impedir a priori este uso, sino sólo regularlo para que dicha facultad se ejerza sin ocasionar daño.

d) Es mérito de Celso, el haber configurado la natruraleza de la titularidad sobre el mar y las costas, en términos de sustraerla de aquella propia de las otras res publicae: D. 43,8,3 pr.-1 (Cel., 39 dig.): "Litora, in quae populus Romanus imperium habet. (1) Populi romani esse arbitror: Maris communem usus omnibus hominibus, ut aeris, iactasque in id pilas eius esse qui iecerit: sed id concedendum non esse, si deterior litoris marisve usus eo modo futurus sit".

El fragmento se encuentra en el título referido al interdicto ne quid in loco publico vel itinere fiat, pero fundamenta el uso libre de las costas, en el hecho de ser estas comunes a todos los hombres y no en el propio de las res publicae, esto es, en la circunstancia de que conciernen a todos los integrantes de populus Romanus $^{88}$.

\footnotetext{
${ }^{87} \mathrm{Ya}$, en varias oportunidades, hemos destacado cómo el aire sólo es referido en dos textos, misma situación que se repite con el aqua profluens. D. 43,8,3,1 (Cel., 39 dig.); D. 47,10,13,7 (Ulp., 57 ed.); D. 39,3,1,22 (Ulp., 53 ed.); C. 3,34,6-7.

${ }^{88} \mathrm{Se}$ puede reforzar lo señalado a propósito de la falta de diversidad en el régimen justinianeo, aludiendo al igual tratamiento jurídico que se da a las res publicae y a las res communes, tal como
} 
e) Este mismo pasaje, da pautas sobre la inclusión del aire en el elenco que posteriormente hará Marciano de las res communes omnium, pero y en esto estamos de acuerdo con lo expuesto por Branca, ello parece ser el resultado de un exceso del maestro tardo clásico, pues Celso no califica el aire como cosa, sino que sólo lo incluye en su sententia como una forma de reforzar la situación que en su opinión tienen las costas.

f) A partir de este momento y cada vez con mayor entidad, los juristas manera más o menos explícita marcan las diferencias entre res publicae y res communes omnium, tal como lo demuestran pasajes de Paulo ${ }^{89}$ e incluso de Ulpiano ${ }^{90}$, el que todavía parece distinguir las res universitatis, de acuerdo a la opinión de Bonfante $^{91}$.

g) El problema, más que de régimen jurídico y fundamento de inclusión en una determinada categoría, que como ya hemos visto, se encuentra en la oscilación del lenguaje, pues los juristas utilizan indistintamente la expresión "res publicae" para referirse a un tipo u otro de cosa.

b) Así, es Marciano quien finalmente le da una configuración propia e incluso un nombre a la nueva categoría de cosa que incluye todas aquellas que, a similitud del mar y sus costas, pueden ser usadas libremente por los hombres por serles comunes. Adicionalmente, este maestro se da a la tarea de realizar un elenco de las mismas y ahí se encuentra su segundo aporte y también el gran error: respecto de las costas y el mar no existe problema alguno, pues como hemos venido repitiendo, son precisamente las que dan origen a la nueva categoría; el aire, ya hemos propiciado, se incluye a propósito de un exceso por parte de MARCIANO, tomado tal vez de la idea de Celso, en orden a reforzar la condición del mar y sus costas; por lo que llegamos al aqua profluens, y sin perjuicio de que tendremos oportunidad de profundizar sobre el tema, la verdad es que con su incorporación lo único que se logró fue dejar en la nebulosa la categoría, pues se trata de una opinión exclusiva de Marciano, que es traída del mundo extrajurídico y particularmente filosófico, a propósito de la idea de que el agua no puede ser negada a nadie ${ }^{92}$ y en consecuencia todos pueden utilizarla, de la misma manera, habrá pensado este maestro, que el aire, el mar y sus costas ${ }^{93}$.

i) En lo que dice relación con el régimen, nos parece que aquí debemos jugar también con la época, pues hacia finales del siglo I d.C., se nota una evolución que lleva a diferenciar dentro de aquella, hasta entonces, general categoría de res publicae. Precisamente, podemos apreciar hacia el periodo señalado una constante diversidad de opiniones en cuanto a la calificación de las cosas, de las que dan

lo demuestra la inclusión de este fragmento de Celso en el título indicado, sin reparar en que se refiere a cosas que previamente han sido calificadas como res communes omnium.

${ }^{89}$ D. 18,1,34,1 (Paul., 32 ed.); D. 18,1,51 (Paul., 21 ed.)

${ }^{90}$ D. 39,1,1,17-18 (Ulp., 52 ed.); D. 43,1,1, pr. (Ulp., 10 ed.); D. 43,8,2,8 (Ulp., 68 ed.); D. 48,8,2,2 (Ulp., 68 ed.).

${ }^{91}$ Bonfante, Pietro, Corso di Diritto Romano. La proprietà, cit. (n. 26), p. 89.

${ }^{92}$ Cic., De off. 1,16,51.

${ }^{93}$ Subrayamos en este sentido, las influencias filosóficas que son evidentes en este caso para entender la opinión de Marciano. 
muestras vestigios que nos han llegado a través de las fuentes, y en las que se pueden apreciar dudas en la jurisprudencia respecto del encasillamiento de algunas cosas. En fin, existen algunas cosas que son comunes a todos y su uso no puede prohibirse a nadie, pero, a su vez, también existen otras que comparten la misma característica de utilización común, sin embargo que dicho uso puede ser vetado: las primeras son res communes omnium, las segundas res publicae y res universitatis. Se trata de un esfuerzo por ordenar las cosas que no admiten reivindicación y de explicar las facultades que se pueden ejercer respecto de ellas, así como también de su fundamento: el libre uso de las res communes omnium deriva de su destinación natural, a diferencia de las otras, en las que este uso común deriva de la participación e integración al populus o a una civitas. Esto trae consecuencias, pues tal como ha afirmado BRANCA, en el primer caso se trata de regular el uso en relación con los otros; mientras que en el segundo la cuestión es más compleja pues además de lo anterior se debe fojar la situación con la "entidad" pública que corresponda.

En suma, las res del primer grupo serían consideras communes por ius naturale, derivado de la naturalis ratio o de la naturaleza misma de la cosa, teniendo una especie de falta de idoneidad física para ser objeto de propiedad o posesión de los particulares y siendo entonces además extra commercium $^{94}$.

\section{La situación en el "Corpus Iuris".}

Queda por encuadrar la categoría de las res communes omnium, en el Corpus Iuris y para ello, a lo menos debemos recordar ciertos fragmentos que están incluidos en nuestra base textual y que presentan una clara influencia marcianea. Punto de partida para el discurso siguiente se encuentra en las Institutas de Justiniano, pues en el Título I del Libro II, después de la enunciación general que es tomada de Gayo $^{95}$ (res in nostro patrimonio-res extra patrimonium nostrum habentur), los compiladores insertan la clasificación tomada de las Institutiones de Marciano ${ }^{96}$ : Inst. 2,1 pr.: "Superiore libro de iure personarum exposuimus: modo videamus de rebus. Quae vel in nostro patrimonio vel extra nostrum patrimonium habentur. Quaedam enim naturali iure comuna sunt omnium, quaedam publica, quaedam universitatis, quaedam nullius, pleraque singulorum, quae variis ex causis cuique adquiruntur, sicut ex subiectis apparebit".

A este texto podemos adicionar otro, extraído de la misma fuente: Inst. 2,1,1: "Et quidem naturali iure comuna sunt omnium haec: aer et aqua profluens et mare et per hoc litora maris. Nemo igitur ad litus maris accedere prohibetur, dum tamen villis et monumentos et aedificiis abstineat, quia non sunt iuris gentium, sicut et mare".

A su vez, y como tuvimos oportunidad de advertir en su oportunidad, este mismo texto lo podemos encontrar en el Digesto, específicamente en el título

\footnotetext{
${ }^{94}$ Pampaloni, Muzio, Sulla condizione giuridica delle rive del mare in diritto romano e odierno, en BIDR., 4 (1891), pp. 212 ss.

${ }^{95}$ Inst. 2,1 pr.

${ }^{96}$ No deja de ser curioso el hecho de que los compiladores se hayan separado del esquema presentado por Gayo y hayan seguido el camino de Marciano, aunque si tal vez, la sistemática de este último servía con mayor entidad para los fines propuestos.
} 
$8^{\circ}$ del libro I, pero con una alteración: prescinde de las res publicae. Se trata de D. 1,8,2 (Marcian., 3 inst.) : "Quaedam naturali iure communia sunt omnium, quaedam universitatis, quaedam nullius, pleraque singulorum quae variis ex causis cuique adquiruntur. et quidem naturali iure omnium comuna sunt illa: aer, aqua profluens, et mare, et per hoc litora maris".

Una primera cuestión que debemos enfrentar, entonces, es la vinculada a la falta de concordancia de las fuentes citadas, pues como ya hemos dicho, el último fragmento recién reproducido, está tomado de las Institutiones de Marciano, cuya influencia es innegable en la redacción del pasaje respectivo de las Institutas justinianeas, y en él no se mencionan las res publicae. Para Bonfante ${ }^{97}$, el asunto se resuelve de manera bastante sencilla, pues sostiene que no es descartable que con la expresión res communes omnium, se designe a las mismas res publicae, de tal manera que la ausencia de éstas en la clasificación presentada en el Digesto, sería mas aparente que real, ya que se encontrarían incluidas, pero con otro nombre: res communes omnium. Es decir, que entre las denominadas res communes y las res publicae, nunca existió una real diferenciación, pues en su opinión, en los límites de un Estado, todo aquello que no está bajo el dominio de los particulares, se termina por reconducir a una vaga y abierta categoría de dominio público.

Nos inclinamos por rechazar esta teoría, dado que existen demasiados vestigios que dan cuenta de que la diversidad entre res publicae y res communes omnium, no sólo es existente, sino que estaba muy presente en Marciano, lo que impide seguir con la tesis de que éste habría confundido en una sola, ambas categorías. De hecho, esta opinión está en plena coincidencia con lo indicado oportunamente por Grosso, cuando señala que la ausencia de las res publicae en el pasaje del Digesto sólo se puede explicar por dos vías, siendo la primera el suponer que Marciano ignoraba la categoría y, la segunda, que la alusión fue borrada accidentalmente por un copista. Al igual que nuestro autor, nos pronunciamos a favor de esta última hipótesis y, especialmente, fundado en la circunstancia de que Marciano, tal como lo ha demostrado Branca, tenía muy presente la diferencia entre res publicae y res communes, pues respecto de las primeras y en cuanto a su régimen, no se trata sólo de regular su uso, tal como ocurre en el caso de las segundas, si no también de regular las relaciones de los privados con la autoridad. Por lo demás, el criterio que justifica el uso para todos de estas dos categorías de cosas es diferente: en las res communes se usan como propias; en cambio, en las res publicae dicho uso común deriva de la destinación misma de la cosa. Entonces, las res communes no sin ni del populus Romanus, ni de una colectividad organizada y la diferenciación está presente incluso en Celso y Ulpiano, por lo que no pudo menos que ser conocida por Marciano.

En definitiva, Marciano señala que la mayor parte de las cosas son susceptibles de pertenencia privada y respecto de aquellas que no lo son, algunas no pertenecen a nadie y otras a todos: una colectividad organizada, el Estado o el género humano. Precisamente en torno a estas últimas, en cuanto falta dicha organización o era absurdo que el Estado destinara la cosa al uso de todos los hombres, se comienza

${ }^{97}$ Bonfante, Pietro, Corso di Diritto Romano. La proprietà, cit. (n. 26), pp. 41 ss. 
a configurar la categoría de las res communes omnium. Siguiendo esta misma línea, pero con otros argumentos, se pronuncia Scherillo, dado que termina por señalar que desde la época del emperador Trajano, la jurisprudencia comenzó a perfilar un régimen especial para el mar y sus costas, régimen en el que más tarde se comienza a distinguir con el carácter de autónoma las res communes omnium. Así, concluye nuestro autor, Marciano al final de la evolución no hace más que formular expresamente el pensamiento de Ulpiano, que ya estaba presente en Neracio y Celso.

Queda, en nuestro concepto superado este primer obstáculo respecto del encuadramiento de las res communes omnium: la versión que nos transmite el Digesto, respecto de la clasificación de las cosas de Marciano, no incluye las res publicae, debido a la alteración no intencional del mismo, originada en la falta de un copista.

Entonces, partiendo de la base previamente expuesta podemos ordenar la clasificación de Marciano, en lo que a nosostros concierne, en los siguientes términos: $i$ ) hay res communes a todos por ius naturale; $i$ ) existen res publicae, que son aquellas en que hay interés del populus Romanus; iii) semejantes a las anteriores, son las res universitatis, que guardan relación con una colectividad (municipia, colonia); iv) existen res nullius, que no pertenecen a nadie y en las que este maestro incluye las res sacrae, res religiosae y res sanctae; y $v$ ) por último, están las res que pertenecen a los privados y que constituyen el grupo más numeroso.

No resulta difícil concluir, que la clasificación se presenta no sólo en términos más sencillos a la que hace Gayo, sino que mucho más cómoda para los requerimientos de la realidad y del derecho justinianeo. Esto mismo motiva, que en el Corpus Iuris se haya incluido tanto la idea gayana como la marcianea, pero sin tener la pretensión de concordarlas, sino sólo como la conclusión final en la que ahora interesa marcar la estructura de la clasificación de las res desde el binomio res publica-res privata, manteniendo el criterio de la pertenencia como fundante de la misma. Entonces, si se nos permite teorizar, tal vez si la clave para entender el asunto se encuentre en la cada vez más fuerte tendencia a la unificación de los bienes que no pertenecen a los privados: si miramos con atención la clasificación de Marciano, subyace en ella una gran diferenciación: las res que pertenecen o pueden pertenecer a los privados, en razón de aquellas que no admiten esa posibilidad, exactamente lo que interesa remarcar al Corpus Iuris.

Todavía más, y en este orden seguimos a Branca, la inexistencia de diferenciación entre las res communes, las res universitatis y las res publicae, es totalmente palpable en el derecho justinianeo, por lo que la misma diversidad no tiene sentido.

Así, en nuestra opinión, finaliza el proceso iniciado hacia la época del Principado y que ha destacado Scialoja ${ }^{98}$, cuando se forma el fiscus Caesaris, cuyo titular, como muy bien señala Guzmán Brito ${ }^{99}$, es el Príncipe en cuanto tal (no como persona privada) y que progresivamente va absorbiendo al aerarium del populus

\footnotetext{
${ }^{98}$ SCIALOJA, Vittorio, Teoria della proprietà nel diritto romano, cit. (n. 32), p. 237.

${ }^{99}$ GuZmán Brito, Alejandro, Derecho Privado Romano (Editorial Jurídica de Chile, Santiago, 2006), I, pp. 442 ss.
} 
Romanus $^{100}$. Como consecuencia de este fenómeno, todas aquellas cosas que según la terminología clásica eran res publicae en los varios sentidos que se puede dar a esta palabra, tendieron a subsumirse en una misma categoría.

En razón de lo anterior, llegados a la época justinianea, realmente lo que interesa diferenciar son las cosas cuya pertenencia es pública (que se pueden ubicar bajo el título general de res publicae, tal como ya hemos dicho) y aquellas que son de particulares. Por eso y dada la identidad de régimen jurídico, se desatiende a la falta de concordancia que representa la ausencia o presencia de las res publicae, pues da lo mismo la nomenclura que se les de: todas ellas son res publicae, en general.

Un último punto por aclarar sería el de la persistencia la nomenclatura clásica y no parece absurdo pensar en un resabio que mantiene el respeto por las categorías históricas, fenómeno que no es aislado, pues como claramente lo ha demostrado $\mathrm{Zoz}^{101}$, esto mismo sucede con las res sanctae.

\section{EL EXAMEN DEL ELENCO DE LAS "RES COMMUNES OMNIUM" Y CRÍTICA A LA INCLUSIÓN DEL AIRE Y DEL "AQUA PROFLUENS" POR PARTE DE MARCIANO}

Somos de la opinión que las res communes omnium no son una creación original de Marciano ${ }^{102}$, sino que el mérito de este maestro tardo-clásico, se reduce a darles una autonomía que antes de él no existía, pero que estaba perfectamente perfilada desde Celso. También hemos señalado que sin perjuicio del aporte previamente referido, en lo que si existe una total originalidad por parte de Marciano, es en la inclusión de lo que él denomina como "aqua profluens" en la categoría, hecho que, desde antaño, ha suscitado profundas controversias en la romanística ${ }^{103}$.

En fin, de acuerdo a las propias palabras de Marciano, según la versión que nos ha llegado de su obra, en aquella parte que es pertinente, a través del Digesto, por ius naturale el aire, el aqua profluens, el mar y sus costas, todos objeto de naturaleza física diversa, son res communes omnium, es decir destinadas al uso común e indistinto de todos los hombres.

Para nosotros, el gran problema se encuentra cifrado en las dos primeras cosas

${ }^{100}$ De Martino, Francesco, Storia della costituzione romana, cit. (n. 8), IV, pp. 803 ss.

${ }^{101}$ Zoz, María Gabriela, Riflessioni in tema di res publicae (Torino, Giappchelli, 1999), p. 31.

${ }^{102}$ En contra, véase Dell'Oro, Aldo, Le “res communes omnium” dell'elenco di Marciano e il problema dell loro fondamento giuridico, en Studi Urbaniti, 31 (1962-1963), pp. 239 ss. En muchas ocasiones seguiremos tanto el esquema como algunas opiniones de este autor, lo que no resulta sorprendente, particularmente por la calidad de su obra.

${ }^{103}$ De Giovanni, Giuristi Severiani. Elio Marciano, cit. (n. 2), p. 35. Este autor, descarta la tesis de Bonfante en orden a que la inclusión del aqua profluens en la categoría, sea producto de un sofisma y en definitiva de una concesión de Marciano a las influencias filosóficas que son evidentes en él. Por el contrario, indica que se trataría de una de las manifestaciones de que Marciano sería el autor de una nueva clasificación de las cosas, que incluye por primera vez y de manera inédita la categoría de res communes omnium. Esta vez estamos más cercanos a la opinión de Bonfante. 
antes señaladas, pues respecto del mar y sus costas, en la medida que ellas sean entendidas como el punto de arranque de la categoría, no existe discusión en cuanto a su inclusión en el elenco. Precisamente por esto, y especialmente por el hecho de que detenernos más profundamente en ellas, nos llevaría a realizar el análisis del régimen jurídico de las mismas, es que sólo nos referiremos con mayor detención al aire y al aqua profluens. Dejaremos para otra oportunidad el análisis del mar y sus costas, sin perjuicio de las apreciaciones generales que señalaremos oportunamente.

1. El aire.

Es de lo que menos se habla en las fuentes ${ }^{104}$ en cuanto en una sociedad antigua, no es susceptible de apropiación o disfrute económico y no puede concebirse más que como una cosa de la cual todos pueden gozar indistintamente. Pese a esto, hay algunos autores ${ }^{105}$ que sostienen que Marciano se estaría refiriendo a las corrientes de aire, las que si tienen importancia, por ejemplo para la navegación, pero a nosotros nos parece que ello es absolutamente descartable ${ }^{106}$, especialmente por el hecho de que no resulta evidente esta disquisición por parte de Marciano ni de la jurisprudencia en general, lo que se denota en la falta de referencia en las fuentes.

Parece ser que la inclusión en el elenco de res communes omnium del aire, se debe más bien a la influencia filosófica o, como hemos propuesto, a un abuso de la opinión de Celso, quien sin calificar el aire como cosa, lo trae a colación para el sólo efecto de profundizar su opinión respecto de lo que sucede con las $\operatorname{costas}^{107}$. De hecho, y como hemos tenido oportunidad de aclarar, el aire no puede ser considerado una res desde el punto de vista técnico, pues respecto de él es absolutamente imposible el ejercicio de la reivindicatoria ${ }^{108}$.

Ahora bien, si nos remitimos a las fuentes, resulta ser que el aire es citado sólo dos veces, en D. 43,8,3,1 (Cel., 39 dig.) y D. 47,10,13,7 (Ulp., 57 ed.) y en ambos casos se le utiliza para marcar una equiparación ya sea con el mar o con sus costas.

Así, nos parece razonable la posición de Robbe ${ }^{109}$, en orden a considerar absurda la inclusión del aire en el elenco de las res communes omnium y, todavía más general, en su calificación de res. La destinación natural del aire para ser utilizado por todos y particularmente el hecho de que no es susceptible de apropiación, la verdad en virtud de su propia consistencia, nos hacen coincidir con la opinión de este romanista: no se puede privar al hombre del aire, pues se estaría privando de la vida. Por lo mismo, se encuentra absolutamente ajeno a consideraciones jurídicas y trasciende al ámbito del derecho.

${ }^{104}$ SCIALOJA, Teoria della proprietà nel diritto romano, cit. (n. 32), p. 125 ss.

${ }^{105}$ Véase, por todos, Perozzi, Istituzioni di diritto romano, cit. (n. 21), p. 596 n.1.

${ }^{106}$ Dell'Oro, Aldo, Le "res communes omnium" dell'elenco di Marciano e il problema dell loro fondamento giuridico, cit. (n. 106), p. 271.

${ }^{107}$ D. 43,8,3 (Cel. 39 dig.).

${ }^{108}$ En el mismo sentido, pero con otros argumentos, véase RoBBE, cit. (n. 14), pp. 377 ss.

${ }^{109}$ RobBe, Ubaldo, cit. (n. 14), pp. 380 ss. 


\section{El "aqua profluens".}

El caso del aqua profluens requiere de una atención más profunda que el caso del aire, entre otros aspectos porque aun no existe consenso siquiera en cuanto a qué debe entenderse con esta expresión.

Para Scialoja ${ }^{110}$, no se trata de cualquier masa de agua, sino de aquella que se caracteriza por ser "profluens", esto es "agua en movimiento". Pero la precisión no termina con la controversia, por que todavía debemos definir de qué agua en movimiento se trata y frente a la alternativa de que la referencia se haga respecto de aquella agua que escurre por cursos abiertos o también incluir aquella que lo hace a través de canales artificiales y especialmente tuberías, nuestro autor termina inclinándose a favor de la primera ${ }^{111}$.

Así no resulta extraño que nuestro autor, califique la situación del aqua profluens como el punto más difícil y delicado de la teoría de las res communes ${ }^{112}$, todavía más si consideramos que de acuerdo a la paráfrasis griega de las Institutas atribuída a Teófilo, a ella se le identifica con el "aqua perennis", lo que no parece ser muy razonable ${ }^{113}$; misma conclusión que se puede sacar de la tesis que pretende asimilarla con el aqua pluvia.

Ahora, continúa Scialoja, parece que lo correcto es entender que aqua profluens, es aquella que escurre por los ríos u otros cursos naturales, en contraposición de aquella que lo hace por tubos o cañerías, ambas obras artificiales.

Sin embargo, aquí podemos notar un aspecto importante para nuestra tesis: si el aqua profluens, es el agua que escurre por cursos de agua (y parece que ese debe ser el correcto sentido ${ }^{114}$ ) y ella es calificada dentro de la categoría de res communes omnium; no debemos olvidar que a lo menos los flumina pueden ser clasificados como públicos o privados de acuerdo al carácter perenne de las aguas. La lógica conclusión de este esquema es que se trata de dos cosas distintas: una constituida por el curso de agua y otra por el agua que escurre por él.

Todavía debemos agregar algo más: en nuestro concepto el aqua profluens no puede ser calificada de res en el sentido técnico, por la misma razón que argumentábamos a propósito del aire: no admite la posibilidad de ser reivindicada, pues no es individualizable. Pero unida a esta similitud existe una diferencia no menor: respecto del aire no existe posibilidad, ni material ni jurídica, de privar a nadie; en cambio del agua si, aunque por una vía indirecta, esto es mediante la prohibición de acceder a los cursos de agua, derivados del ejercicio del dominium por parte del titular del predio donde se encuentra la fuente cualquiera sea esta.

Vale recordar entonces, lo expuesto en su oportunidad en cuanto que aquello que puede ser calificado como público o privado son los flumina y no el agua que escurre por ellos, en relación a la cual dicha calidad no se comunica o traspasa: el binomio no es aqua plublica-aqua privata; sino flumina publica-flumina privata.

${ }^{110}$ Teoria della proprietà nel diritto romano, cit. (n. 32), pp. 126 ss. y 135 ss.

${ }^{111}$ Ibíd., p. 398.

${ }^{112}$ Robbe, Ubaldo, cit. (n. 14), pp. 135 ss.

${ }^{113}$ Véase, por todos, Scialoja, Vittorio, cit. (n. 32), p. 128.

${ }^{114}$ En este sentido, otra vez somos ayudados por Cicerón, pues él indica que esta agua es la que escurre en los ríos. Véanse Cic., De off., 1,16,51; 3,16,52. 
Tal vez si en este cúmulo de consideraciones, podemos encontrar la razón por la cual la incorporación del aqua profluens a la categoría de res communes omnium, ha suscitado tanto problemas y finalmente ha terminado por ser considerada sencillamente como una equivocación ${ }^{115}$, siendo demostrativo de ello el hecho de que esta supuesta condición jurídica, no tuvo ninguna resonancia en la jurisprudencia ${ }^{116}$.

Así, no se puede menos que estar de acuerdo con Bonfante, en orden a que Marciano fue inducido por concepciones extrajurídicas para efectos de considerar el agua como una cosa y todavía con similitudes respecto del aire, tal como aparece en Cicerón, cuando declara que el agua no se niega a nadie ${ }^{117}$. Por lo que finalmente debemos concluir que, en el elenco de Marciano, el valor de cada cosa incluida es diverso y en el caso particular del aqua profluens, constituye un error.

Todavía más, Branca ${ }^{118}$, que como hemos visto es uno de los máximos defensores de la clasicidad de la categoría de res communes omnium, entiende que el aqua profluens es un concepto, aislado y privado de consistencia y que tal vez, la expresión es incluida por el propio Justiniano, insertando el agua corriente de los ríos en la primera categoría marcianea para expresar de este modo una solución de continuidad entre ella y las cosas públicas, de este modo se salvaría la reputación de Marciano y de los bizantinos.

Uno de los que más ha profundizado en el tema del aqua profluens es Dell'Oro $^{119}$, precisamente porque de acuerdo a su teoría la creación misma de la categoría de las res comunes omnium como independiente de las res publicae, se debió a la necesidad de MARCIANO de encuadrar adecuadamente este tipo de agua, especialmente motivada por la relevancia que ella adquirió hacia la época en que desarrolló su actividad jurídica ${ }^{120} \mathrm{y}$, especialmente, en lo que dice relación con la utilización de la corriente de los ríos como fuerza motriz para los molinos, lo que requería de la elaboración de principios que fueran favorables a esta iniciativa ${ }^{121}$.

Ya hemos tenido oportunidad de descartar esta tesis, haciéndonos partícipes de las críticas a la misma que ha planteado Capogrossi Colognesi ${ }^{122}$, particularmente porque los supuestos usos que habrían determinado la necesidad de análisis del aqua profluens no son importantes hacia la época en que vivió Marciano ${ }^{123}$,

${ }^{115}$ Véase, por todos, Grosso, Giuseppe, Corso di diritto romano. Le cose, cit. (n. 33), pp. 92; 95; 111 ss. de hecho, ni siquiera las fuentes nos ayudan a llegar a un punto de solución, dado que el concepto de aqua profluens, sólo es citado en dos oportunidades (D. 39,3,1,22 y CI. 3,34,7), pero en ambos casos, absolutamente descontextualizado de las res communes omnium.

${ }^{116}$ RobBe, Ubaldo, cit. (n. 14), p. 395.

${ }^{117}$ De off., 1,16,51-52.

${ }^{118}$ Le cose "extra patrimonium humani iuris", cit. (n. 86), pp. 71 ss.

${ }^{119}$ Dell'Oro, Aldo, Le "res comunes omnium” dell'elenco di Marciano e il problema dell loro fondamento giuridico, cit. (n. 106), pp. 244 ss.

${ }^{120}$ Ibíd., p. 289.

${ }^{121}$ Ibíd., p. 286.

${ }^{122}$ Capogrossi Colognesi, Luigi, Ricerche sulla struttura delle servitù d'acqua in Diritto Romano (Milano, Giuffrè, 1966), pp. 61 ss.

${ }^{123}$ Lo más probable hacia el siglo III de nuestra era. 
elemento fundamental en la tesis de Dell'Oro: por de pronto no existen indicios de en qué medida el transporte de madera por vía de flotación fue utilizada por los romanos y mucho menos del eventual impacto que esta actividad tendría en el régimen jurídico general; por otro lado, la situación del agua como fuerza motriz de los molinos, es desatendible, pues como ya tuvo ocasión de demostrar Bloch $^{124}$ aunque el molino de agua fue conocido por los romanos, la verdad es que su expansión real y su verdadero impacto en la economía y eventualmente en el derecho, data sólo de la época medieval.

Por lo mismo, la conclusión más apropiada es que hacia la época de Marciano la difusión del molino de agua recién estaba en sus inicios y la supuesta falta de mano de obra, otro argumento aludido por Dell'Oro, sólo es efectivamente importante un siglo después de la muerte de nuestro jurista ${ }^{125}$.

\section{El mar y sus costas.}

Como apuntábamos previamente, en el orden de asuntos que ahora nos interesan, la calificación e inclusión del mar y sus costas dentro de las res communes omnium, no puede sorprender y resulta del todo lógica.

Efectivamente, la categoría misma surge a propósito del régimen jurídico del y sus costas, por lo que no puede sorprender que la mayoría de la romanística siga sin más la opinión de Scialoja ${ }^{126}$, quien en verdad no aporta mayores antecedentes, sino que se limita a afirmar que también el mar en el Derecho Romano es entendido como una res communes omnium.

Por lo demás las fuentes nos dan la razón en torno a este argumento.

En primer lugar comparece D. 8,4,13 pr. (Ulp., 6 opin.): "Venditor fundi Geroniani fundo Botriano, quem retinebat, legem dederat, ne contra eum piscatio thynaria exerceatur. quamvis mari, quod natura ómnibus patet, servitus imponi privata lege non potest, quia tamen bona fides contractus legem servari venditionis exposcit, personae possidentium aut in ius eorum suecedentium per stipulationis vel venditionis legis obligantur".

Luego está D. 43,8,3,1 (Cel., 39 dig.): "Maris communem usum monibus hominibus, ut aeris, iactasque in id pilas eius esse qui iecerit: sed in condendum non esse, si deterior litoris marisve usus eo modo futurus sit”.

En fin se presenta D. 47,10,13,7 (Ulp., 57 ed.): “Convicium non tantum praesenti, verum absenti quoque fieri posse Labeo scribit. proinde si quis ad domum tuam venerit te absente, convicium factum esse dicitur. idem et si ad stationem vel tabernam ventum sit, probari oportere".

Respecto de las costas ${ }^{127}$ nos encontramos con el mismo principio, pues el uso del mar también importa el uso de esa franja de terreno, por lo que se extiende la misma calificación de cosa común ${ }^{128}$.

\footnotetext{
${ }^{124} \mathrm{BlOCH}, \mathrm{Marc}$, Avènement et conquête du moulin à eau, en Annales d'historie économique et sociele, en Annales d'historie économique et sociele, 7 (1935), pp. 87 ss.

${ }^{125}$ Capogrossi Colognesi, Luigi, Ricerche, cit. (122), p. 63.

${ }^{126}$ Teoria della proprietà nel diritto romano, cit. (n. 32), p. 127 ss.

${ }^{127}$ D. 50,16,96 (Cel., 25 dig.); D. 50,16,112 (Iav., 11 ex Cass.).

${ }^{128}$ D. 43,8,3,1 (Cel., 39 dig.).
} 


\section{BiBLIOGRAFÍA}

Arangio-Ruiz, Vincenzo, Istituzioni di Diritto Romano (Napoli, Jovene, 1994).

Biondi, Biondo, La condizione giuridica del mare e del "litus maris", en Studi in onore di Silvio Perozzi.

BLOCH, Marc, Avènement et conquête du moulin à eau, en Annales d'historie économique et sociele, en Annales d'historie économique et sociele, 7 (1935).

Bonfante, Pietro, Corso di Diritto Romano. La proprietà (Milano, Giuffre, 1966).

Branca, Giuseppe, Le cose "extra patrimonium humani iuris" (Torino, Giappichelli, 1941).

Buckland, W. W., “Marcian”, en Studi Riccobono, I.

Capogrossi Colognesi, Luigi, Ricerche sulla struttura delle servitù d'acqua in Diritto Romano (Milano, Giuffrè, 1966).

De Giovanni, Lucio, Giuristi Severiani. Elio Marciano (Napoli, M. D’Auria Editore, 1989).

De Giovanni, Lucio, Per un studio delle 'Institutiones' di Marciano, en SDHI., 49 (1983).

De Giovanni, Lucio, Per un studio delle "Institutiones" di Marciano, en SDHI., 49 (1983).

De Martino, Francesco, Storia della costituzione romana (Napoli, Jovene, 19721990).

Dell'Oro, Aldo, Le "res communes omnium" dell'elenco di Marciano e il problema dell loro fondamento giuridico, en Studi Urbaniti, 31 (1962-1963).

FERrini, Contard, Sulla palingensi delle Istituzioni di Marciano, en Opere di Contardo Ferrini, II.

FERrINI, Contardo, Intorno alle Istituzioni di Marciano, en Opere di Contardo Ferrini, II.

Grosso, Giuseppe, Corso di diritto romano. Le cose (Torino, Giappichelli, 1941).

Grosso, Giuseppe, Problemi sistematici nel diritto romano. Cose, contratti (Torino, Giappichelli, 1974).

Grosso, Giuseppe, Rec. a Branca. Le cose extra patrimonium humani iuris, en SDHI., 8 (1942).

Guzmán Brito, Alejandro, Derecho Privado Romano (Editorial Jurídica de Chile, Santiago, 2006), I.

Honoré, A.M., The Severan Lawyers: a Preliminary Survey, en SDHI., 28 (1962).

Miele, Alberto, "Res publica", "res communis omnium", "res nullius": Grozio e le fonti romane sul diritto del mare, en Index, 26 (1988).

Mommsen, Thedoro, Sopra una iscrizione scoperta in Frisia, en BIDR., 2 (1889).

Orestano, Riccardo, s.v. "Marciano Elio", en NNDI., X.

Pampaloni, Muzio, Sulla condizione giuridica delle rive del mare in diritto romano $e$ odierno, en BIDR., 4 (1891).

Pernice, Alfred, Die fogenannten res communes omnium (Berlín, Berlag von \& M. Müller, 1900).

Perozzi, Silvio, Istituzioni di diritto romano (Firenze, Barbera, 1906-1908).

Robbe, Ubaldo, La non classcitá delle "res comunes omnium", en Studi in onore di Andrea Arena, IV.

SCHERILlo, Gaetano, Lezioni di diritto romano. Le cose (Milano, Giuffrè, 1945).

ScHulz, Fritz, History of Roman Legal Science (Oxford, 1935). 
Scialoja, Vittorio, Teoria della proprietà nel diritto romano (Roma, Edita Pietro Bonfante, 1928).

TalamanCA, Mario, Gli ordinamenti provinciali nella prospectiva dei giurisiti tardoclassici, en Atti di un incontro tra storici e giuristi sull tema: istituzioni giuridiche e realità politiche nel tardo impero (III-V sec. d.C.) (Milano, 1976).

Terrazas Ponce, Juan David, El concepto de "res publicae", I: La noción de "res" en el lenguaje de los juristas romanos, en Revista de Estudios Histórico-Jurídicos, 32 (2010).

VILLEY, Michel, Recherches sur la littérature didactique du droit Romain (Paris, 1945). Zoz, María Gabriela, Riflessioni in tema di res publicae (Torino, Giappchelli, 1999). 
